\title{
Coupling the modified SCS-CN and RUSLE models to simulate hydrological effects of restoring vegetation in the Loess Plateau of China
}

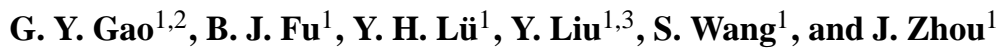 \\ ${ }^{1}$ State Key Laboratory of Urban and Regional Ecology, Research Center for Eco-Environmental Sciences, Chinese Academy \\ of Sciences, 100085 Beijing, China \\ ${ }^{2}$ State Key Laboratory of Soil Erosion and Dryland Farming on the Loess Plateau, Institute of Water and Soil Conservation, \\ Chinese Academy of Sciences and Ministry of Water Resources, Yangling 712100 Shaanxi, China \\ ${ }^{3}$ Lab for Agriculture and Environment, Institute of Remote Sensing Applications, Chinese Academy of Sciences, \\ 100101 Beijing, China
}

Correspondence to: B. J. Fu (bfu@ rcees.ac.cn)

Received: 19 March 2012 - Published in Hydrol. Earth Syst. Sci. Discuss.: 29 March 2012

Revised: 29 June 2012 - Accepted: 29 June 2012 - Published: 28 July 2012

\begin{abstract}
Predicting event runoff and soil loss under different land covers is essential to quantitatively evaluate the hydrological responses of vegetation restoration in the Loess Plateau of China. The Soil Conservation Service curve number (SCS-CN) and Revised Universal Soil Loss Equation (RUSLE) models are widely used in this region to this end. This study incorporated antecedent moisture condition (AMC) in runoff production and initial abstraction of the SCS-CN model, and considered the direct effect of runoff on event soil loss by adopting a rainfall-runoff erosivity factor in the RUSLE model. The modified SCS-CN and RUSLE models were coupled to link rainfall-runoff-erosion modeling. The effects of AMC, slope gradient and initial abstraction ratio on curve number of SCS-CN, as well as those of vegetation cover on cover-management factor of RUSLE, were also considered. Three runoff plot groups covered by sparse young trees, native shrubs and dense tussock, respectively, were established in the Yangjuangou catchment of Loess Plateau. Rainfall, runoff and soil loss were monitored during the rainy season in 2008-2011 to test the applicability of the proposed approach. The original SCS-CN model significantly underestimated the event runoff, especially for the rainfall events that have large 5-day antecedent precipitation, whereas the modified SCS-CN model was accurate in predicting event runoff with Nash-Sutcliffe model efficiency (EF) over 0.85 . The original RUSLE model overestimated
\end{abstract}

low values of measured soil loss and underpredicted the high values with EF values only about 0.30 . In contrast, the prediction accuracy of the modified RUSLE model improved with EF values being over 0.70 . Our results indicated that the AMC should be explicitly incorporated in runoff production, and direct consideration of runoff should be included when predicting event soil loss. Coupling the modified SCS-CN and RUSLE models appeared to be appropriate for evaluating hydrological effects of restoring vegetation in the Loess Plateau. The main advantages, limitations and future study scopes of the proposed models were also discussed.

\section{Introduction}

Flash flood and soil erosion affect adversely the natural and human-management ecosystems. In arid and semi-arid regions, water shortage is the key limiting factor (Wang et al., 2012). Changes in anthropogenic (e.g. land use) and natural (e.g. climate change) forcings will further affect hydrological cycles and water availability at all scales in these regions (Wang et al., 2012; Feng et al., 2012). Therefore, modeling of event- based rainfall-runoff and soil erosion processes under different land use conditions has significant importance, and has fundamental impact on hydrological practices. 
The Soil Conservation Service curve number (SCS-CN) model is a simple and empirical model with clearly stated assumptions and only a few data requirements to estimate runoff for a given rainfall event (Ponce and Hawkins, 1996). It accounts for the major runoff producing characteristics including soil type, land use/treatment, surface condition and soil moisture condition, and incorporates them in a single CN parameter (Ponce and Hawkins, 1996). Mishra and Singh (2003) summarized the application of the SCS-CN model in storm water modeling for single rainfall events, long-term hydrologic simulation as well as predicting infiltration and rainfall-excess rates, and discussed its potential to simulate sediment yield and transport of urban pollutants. The SCS$\mathrm{CN}$ model has also been adopted by many hydrological and ecological models to determine runoff, such as CREAMS (Knisel, 1980), ANSWERS (Beaslry et al., 1980), AGNPS (Young et al., 1989), EPIC (Sharply and Williams, 1990) and SWAT (Neitsch et al., 2005).

On the other hand, the SCS-CN has its own disadvantages. One of the main disadvantages is that there is no explicit guideline on how to change the antecedent moisture condition (AMC) with the antecedent rainfall of certain duration (Ponce and Hawkins, 1996). The standard SCS-CN model incorporates an empirical method to classify AMC into three distinct levels, viz., AMC I (dry), AMC II (normal) and AMC III (wet), based on the amount of 5-day antecedent precipitation $\left(P_{5}\right)$. However, this method usually led to poor results and failure of SCS-CN model to predict runoff (Mishra and Singh, 2002; Huang et al., 2007). Therefore, many studies aimed at improving the method and finding a better way to incorporate the AMC (e.g. Mishra and Singh, 2002; Mishra et al., 2006a; Michel et al., 2005; Huang et al., 2007; Sahu et al., 2010).

The Universal Soil Loss Equation (USLE, Wischmeier and Smith, 1978) and its revised version (RUSLE, Renard et al., 1997) are the most widely used empirical models to predict annual soil loss at field scale resulting from sheet and rill erosion. The USLE/RUSLE models have their advantages over the physical based models such as WEPP and EUROSEM, because they are accurate and easy to use in terms of parameterization. However, their applications to storm-based events usually led to large errors (Kinnell, 2005). Risse et al. (1993) and Tiwari et al. (2000) observed that the USLE/RUSLE models overestimated low values of measured soil loss and underpredicted the high values. This result was mainly due to that runoff and soil loss were considered as separate entities without reference to any intrinsic link between them (Kinnell, 2009). In reality, the linkage between runoff and soil loss is fundamental as the soil lost from the areas of interest is usually discharged across the downslope boundary with surface-water flow (Kinnell, 2010). Therefore, the accuracy of USLE/RUSLE models can be improved if they are coupled with a hydrologic rainfall-excess model.

Mishra et al. (2006b) coupled the SCS-CN method with USLE model to compute the lumped quantity of event sed- iment yield from a number of watersheds. The coupling in Mishra et al. (2006b) was based on three hypotheses that need further verification. Among these hypotheses, two are particularly questionable: (1) the maximum potential retention parameter $(S)$ of SCS-CN model can be expressed in terms of the USLE parameters; and (2) the sediment delivery ratio is equal to the runoff coefficient (Kinnell, 2009). In reality, the logical way to link soil loss and the parameter $S$ should be through the effect of $S$ in predicting runoff ratios rather than through attempts to signify $S$ using USLE (Kinnell, 2009). To consider direct effect of runoff on predicting soil loss, Kinnell (2007) included the runoff ratio in rainfall erosivity index of RUSLE, and applied it to predict event soil loss (Kinnell, 2010; Bagarello et al., 2008, 2010). However, runoff and soil loss modeling was decoupled in their studies as the runoff volume was obtained from measurements, not by model prediction. In addition, the approach was only used in bare plots, and its application in plots with different vegetation types needs further investigation.

The Loess Plateau region is located in the middle reaches of the Yellow River basin in Northern China. This region experiences arid and semi-arid climate conditions over an area greater than $600000 \mathrm{~km}^{2}$ (Lü et al., 2012). It is one of the most severely eroded areas in the world due to highly erodible loessial soil, steep landscape, frequent large rainfall storms in summer months, and low vegetation cover stemming from intensive cultivation and improper land uses (Zhang and Liu, 2005). In order to alleviate soil erosion and improve environmental quality in the Loess Plateau, a series of soil conservation practices such as Grain-for-Green project have being implemented to augment vegetation recovery. Vast areas of cropland in sloping areas were converted into forestland or grassland in the gully and hilly zones of the Loess Plateau, which altered the land use pattern greatly (Cao et al., 2009; Feng et al., 2012). The revegetation resulted in increase of vegetation cover, improvement of soil nutrient levels and recovery of soil properties (Liu et al., 2012). These changes caused significant responses in hydrological function and soil erosion to the abandonment of croplands (Feng et al., 2012). As runoff and soil erosion in the Loess Plateau are often dominated by storms with high intensity or large amount of precipitation in summer (Wei et al., 2009a, b), it is essential to predict event runoff and soil loss with different land covers. This prediction will be of great importance for land use planning and water resources management. The SCS-CN and RUSLE models have been applied at plot (Shen et al., 2003; Huang et al., 2006, 2007; Fu et al., 2011) and watershed scales (Fu et al., 2005; Xiao et al., 2011) in the Loess Plateau. However, few studies have been conducted to explicitly incorporate AMC in SCS-CN model, except that Huang et al. (2007) developed an equation between curve number and soil moisture to account for AMC. There is no study that includes direct consideration of runoff in predicting event soil loss and links runoff with soil loss simulation, which will be the focus of this investigation. 
The objectives of this study are as follows: firstly, to incorporate AMC in runoff production and initial abstraction of the SCS-CN model, and consider the direct effect of runoff on event soil loss by adopting a rainfall-runoff erosivity factor in the RUSLE model; secondly, to couple the modified SCS-CN and RUSLE models with the rainfall-runoff-erosion modeling and; thirdly, to apply the proposed approach to predict event runoff and soil loss from restored vegetation plots in the Loess Plateau of China.

\section{Model theory}

\subsection{Rainfall-runoff modeling}

\subsubsection{Original SCS-CN model}

The SCS-CN method is based on the principle of the water balance and two fundamental assumptions (Mishra and Singh, 2002). The first assumption is that the ratio of direct runoff to potential maximum runoff is equal to the ratio of infiltration to potential maximum retention. The second assumption states that the initial abstraction is proportional to the potential maximum retention. The water balance equation and the two assumptions are expressed mathematically:

$P=I_{\mathrm{a}}+F+Q$

$\frac{Q}{P-I_{\mathrm{a}}}=\frac{F}{S}$

$I_{\mathrm{a}}=\lambda S$

where $P$ is the total precipitation $(\mathrm{mm}), I_{\mathrm{a}}$ is the initial abstraction before runoff (mm), $F$ is the cumulative infiltration after runoff begins (mm), $Q$ is direct runoff (mm), $S$ is the potential maximum retention $(\mathrm{mm})$, and $\lambda$ is the initial abstraction coefficient. Combination of Eqs. (1) and (2) leads to the popular form of the original SCS-CN method:

$$
\begin{aligned}
& Q=\frac{\left(P-I_{\mathrm{a}}\right)^{2}}{P-I_{\mathrm{a}}+S} \text { for } P>I_{\mathrm{a}} \\
& Q=0, \quad \text { for } P \leq I_{\mathrm{a}}
\end{aligned}
$$

The parameter $S$ can vary in the range of $0 \leq S \leq \infty$, and it is directly linked to the curve number $\mathrm{CN}$ :

$S=\frac{25400}{\mathrm{CN}}-254$

where the $\mathrm{CN}$ is a dimensionless variable, and it depends on land use, hydrological soil group, hydrologic conditions, and antecedent moisture conditions.

\subsubsection{Modified SCS-CN model}

The variability of antecedent rainfall and the associated soil moisture amount is an important source of the inherent curve number variability encountered in applications of the SCSCN method (Ponce and Hawkins, 1996). The incorporation of antecedent moisture in the original SCS-CN method in terms of three AMC levels permits unreasonable sudden jumps in the $\mathrm{CN}$-variation, which results in corresponding jumps in computed runoff (Mishra et al., 2006a). To circumvent these problems, Mishra and Singh (2002) suggested an SCS-CN-based equation incorporating antecedent moisture and $P_{5}$ for computation of runoff.

Using the $C=S_{\mathrm{r}}$ concept, where $C$ is the runoff coefficient $\left(=Q /\left(P-I_{\mathrm{a}}\right)\right)$ and $S_{\mathrm{r}}$ is the degree of saturation, Mishra and Singh (2002) modified the original SCS-CN method for accounting antecedent moisture $M$ :

$\frac{Q}{P-I_{\mathrm{a}}}=\frac{F+M}{S+M}$

where $M$ is antecedent moisture representing the amount of moisture available in the soil profile before the start of the storm (mm).

Substituting Eq. (6) into Eq. (1) leads to

$Q=\frac{\left(P-I_{\mathrm{a}}\right)\left(P-I_{\mathrm{a}}+M\right)}{P-I_{\mathrm{a}}+M+S}$.

The $M$ on the day of onset of rainfall is assumed to be the amount of water infiltrated due to the antecedent 5-day rainfall $(M=F)$, prior to which the soil is completely dry:

$M=P_{5}-I_{\mathrm{a}}-Q$.

Assuming the antecedent moisture condition to be dry for 5 days before the onset of the considered rain storm, substituting Eq. (4) into Eq. (8) results in the expression of $M$ (Mishra and Singh, 2002):

$M=\frac{\left(P_{5}-\lambda S_{\mathrm{I}}\right) S_{\mathrm{I}}}{P_{5}+(1-\lambda) S_{\mathrm{I}}}$

where $S_{\mathrm{I}}$ is the potential maximum retention corresponding to the AMC I condition (mm). Since $S_{\mathrm{I}}=S+M$, it follows

$M=0.5\left[-(1+\lambda) S+\sqrt{(1-\lambda)^{2} S^{2}+4 P_{5} S}\right]$.

Here + sign before the square root is retained for $M \geq 0$, and $P_{5} \geq \lambda S$.

In the original SCS-CN method, $I_{\mathrm{a}}$ is given by Eq. (3), which does not incorporate $M$. In reality, the initial abstraction, which represents losses due to interception, surface storage, evaporation, and infiltration, varies inversely with the antecedent moisture. The higher the antecedent moisture, the lower will be the initial abstraction, and vice versa (Mishra et al., 2006a). Mishra et al. (2006a) modified Eq. (3) to the 
following non-linear $I_{\mathrm{a}}-S$ relation incorporating antecedent moisture:

$I_{\mathrm{a}}=\frac{\lambda S^{2}}{S+M}$

For a completely antecedent dry condition or $M=0, I_{\mathrm{a}}=$ $\lambda S$, which is the same as Eq. (3). Substituting Eq. (11) into Eq. (7), one can obtain the simulated event runoff of the modified SCS-CN method:

$Q=\frac{\left(P-\frac{\lambda S^{2}}{S+M}\right)\left(P-\frac{\lambda S^{2}}{S+M}+M\right)}{P-\frac{\lambda S^{2}}{S+M}+M+S}$

\subsection{Soil loss modeling}

\subsubsection{Original RUSLE model}

The USLE/RUSLE models predict long-term average annual soil loss using six factors that are associated with climate, soil, topography, vegetation and management. They have also been used for time intervals shorter than the mean annual one, such as the event scale (Kinnell, 2005; Bagarello et al., 2010):

$A_{\mathrm{e}}=R_{\mathrm{e}} K \operatorname{LSCP}$

where $A_{\mathrm{e}}$ is the event soil loss ( $\left.\mathrm{tha}^{-1}\right), R_{\mathrm{e}}$ is the event rainfall erosivity factor ( $\mathrm{MJ} \mathrm{mm} \mathrm{ha}{ }^{-1} \mathrm{~h}^{-1}$ ) given by the product of total kinetic energy of the rainstorm $\left(E, \mathrm{MJ} \mathrm{ha}^{-1}\right)$ and maximum 30-min intensity during the event $\left(I_{30}, \mathrm{~mm} \mathrm{~h}^{-1}\right)$ $\left(R_{\mathrm{e}}=\mathrm{EI}_{30}\right), K$ is the soil erodibility factor $\left(\mathrm{th} \mathrm{MJ}^{-1} \mathrm{~mm}^{-1}\right)$, LS is the slope-length and steepness factor, $C$ is the covermanagement factor, and $P$ is the conservation supportpractice factor.

\subsubsection{Modified RUSLE model}

Many studies have indicated that the USLE/RUSLE overestimated low event soil losses and underestimated high event soil losses (Kinnell, 2005, 2007, 2010). The failure to consider runoff explicitly is a primary factor for USLE/RUSLE model to produce systematic errors in the prediction of event erosion (Kinnell, 2005). In reality, erosion is a hydrologically driven process, and it is well known that event soil loss is given by the product of the runoff amount and bulk sediment concentration for an event (Kinnell, 2005; Bagarello et al., 2010). Modern understanding of rainfall erosion processes recognizes that runoff is a primary independent factor in modeling rainfall erosion. To directly consider the effect of runoff, Kinnell (2007) proposed the event rainfall-runoff erosivity index $\left(Q_{\mathrm{R}} \mathrm{EI}_{30}, Q_{\mathrm{R}}\right.$ is the runoff ratio) to replace the USLE/RUSLE rainfall erosivity factor $\left(\mathrm{EI}_{30}\right)$, and substantial improvement of prediction accuracy was obtained (Kinnell, 2007, 2010). Bagarello et al. (2008, 2010) found that the event soil loss was proportional to the power function of
$Q_{\mathrm{R}} \mathrm{EI}_{30}$ term. In terms of above results, the following modified RUSLE model is used to predict event soil loss:

$A_{\mathrm{e}}=a\left(Q_{\mathrm{R}} \mathrm{EI}_{30}\right)^{b} K \operatorname{LSC} P$

where $a$ and $b$ are empirical coefficients.

Equation (14) differs from both the USLE-M by Kinnell (1998) and the USLE-MM by Bagarello et al. (2010). In the USLE-M, the proportionality between $A_{\mathrm{e}}$ and the erosivity term $Q_{\mathrm{R}} \mathrm{EI}_{30}$ is direct, i.e. the coefficient $b$ is equal to one. The USLE-MM includes an exponent for the $Q_{\mathrm{R}} \mathrm{EI}_{30}$ term with $b$ greater than one. As noted by Kinnell $(1998,2010)$, changing the event rainfall-runoff factor from the $\mathrm{EI}_{30}$ index has consequences on a number of the other factors used in the model. In particular, the original soil erodibility factor cannot be used to predict soil loss. In the USLE-M, a new value of the soil erodibility $\left(K_{\mathrm{UM}}\right)$ is used, while in the USLEMM the $a$ coefficient is considered to be representative of soil erodibility. However, it is difficult to directly determine the new soil erodibility. In Eq. (14), the original soil erodibility is used, and the coefficient $a$ is used to account for the effects of changing rainfall erosivity in a simple way. In this way, the modified RUSLE model can encompass both the USLE-M and USLE-MM.

In the modified RUSLE model, the effects from event rainfall and runoff on soil loss as well as the impact of event erosivity index on other factors are explicitly considered. The predicted event runoff of the modified SCS-CN method is substituted into Eq. (14) to determine $Q_{\mathrm{R}}$. In this way, the event rainfall-runoff-erosion modeling is directly coupled, which is very useful for practical application.

\section{Model application}

\subsection{Study area}

The study area is the Yangjuangou catchment $\left(36^{\circ} 42^{\prime} \mathrm{N}\right.$, $109^{\circ} 31^{\prime}$ E) located in the middle part of the Loess Plateau, Shaanxi Province, China (Fig. 1). The catchment has a total area of $2.02 \mathrm{~km}^{2}$ with elevation ranging from $1050 \mathrm{~m}$ to $1298 \mathrm{~m}$. It is a typical gully and hilly area with a gully density of $2.74 \mathrm{~km} \mathrm{~km}^{-2}$, and the slope gradients range from $10^{\circ}$ to $30^{\circ}$ ( $\mathrm{Li}$ et al., 2003). The area has a semi-arid continental climate with an average annual rainfall of $535 \mathrm{~mm}$. The rainfall is mainly concentrated between June and September with large inter-annual variations. Soil in the study area is mainly derived from loess, which is fine silt to silt in texture. The soil type is Calcaric Cambisol characterized by a uniform texture and weak structure, and it is vulnerable to water erosion ( $\mathrm{Li}$ et al., 2003). The average erosion rate of the Yangjuangou catchment was $90.42 \mathrm{tha}^{-1} \mathrm{yr}^{-1}$ between 1980 and 1990 and $62.73 \mathrm{tha}^{-1} \mathrm{yr}^{-1}$ during 1992-1996 (Li et al., 2003), and $36.41 \mathrm{t} \mathrm{ha}^{-1} \mathrm{yr}^{-1}$ in 2006 (Wang et al., 2009).

Before the 1980s, the land use in the Yangjuangou catchment was dominated by croplands. Reforestation began in 


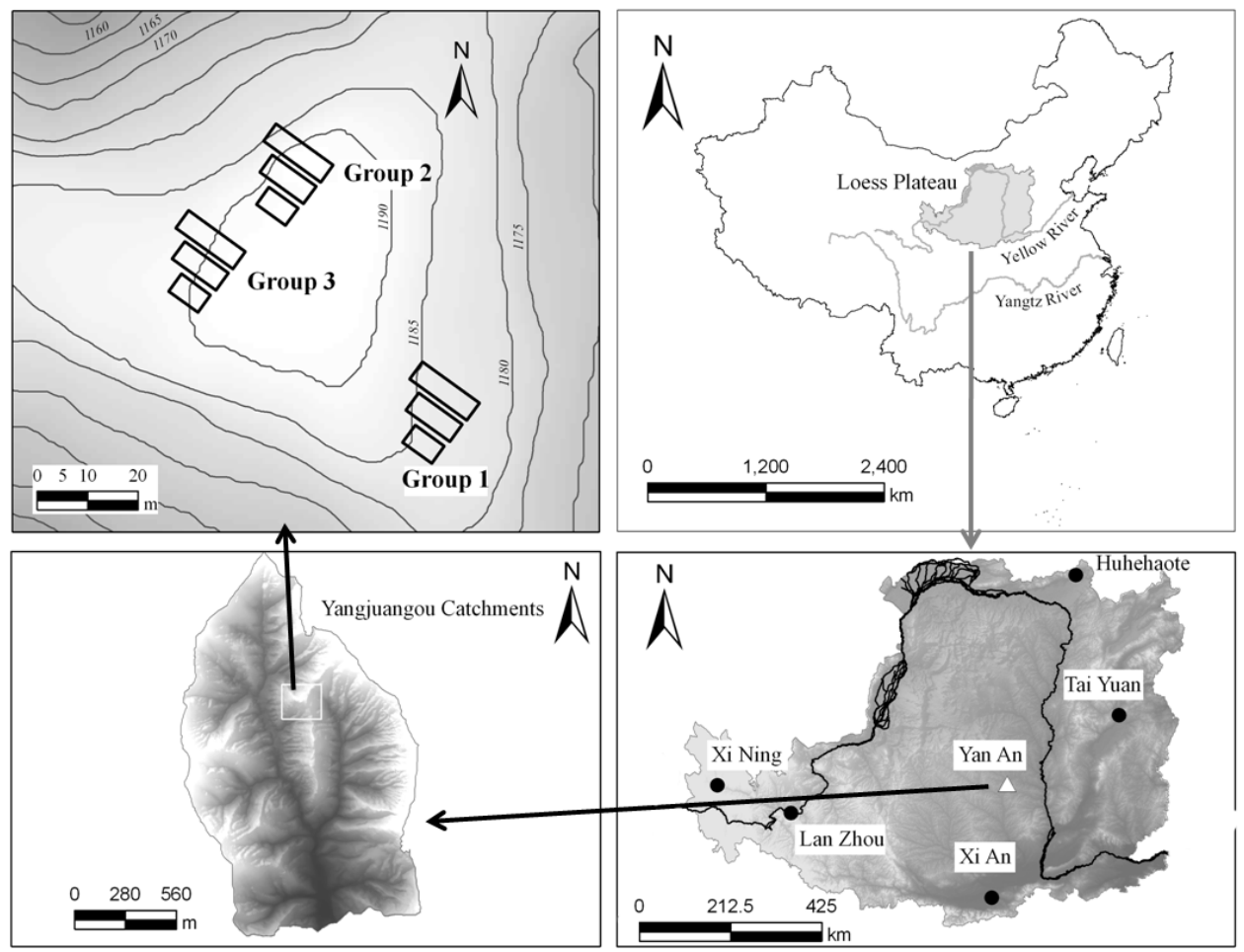

Fig. 1. Location of the study area and distribution of the three runoff plot groups.

the 1980s on infertile and steep cultivated lands with low crop yields. Driven by the implementation of the Grain-forGreen project since 1998, most of the cultivated lands on steep slopes have been abandoned for natural or artificial revegetation. At present, the main land use types are grassland, forestland and shrubland formed at different restoration stages. The main forest species in the Yangjuangou catchment is acacia (Robinia pseudoacacia), which was planted in the 1980s or after 1999. The dominant grass species are Artemisia sacrorum, Stipa bungeana and Artemisia scoparia. The main shrub species are Prunus armeniaca and Hippophae rhamnoide. As a result of human disturbances and changes of the natural environmental conditions, mosaic of patchy land cover is the typical landscape pattern in the Yangjuangou catchment.

\subsection{Data collection}

Three runoff plot groups with different land cover types were installed in the catchment in 2008 (Figs. 1 and 2). Each group included three closed runoff plots with a fixed width of $2 \mathrm{~m}$ and lengths of 5, 9 and $13 \mathrm{~m}$, respectively. Two numbers were used to define the runoff plot. For example, plot 11, plot 12 and plot 13 indicated that these plots belonged to Group 1 and their lengths were 5, 9 and $13 \mathrm{~m}$, respectively. The slope gradients of all plots were somewhat different (see Table 1). Each plot was surrounded by inserting galvanized iron sheets into soil with depth of $10 \mathrm{~cm}$ on the upper and side bound- aries. The lower boundary of the plots was made of gutter, which collected and channeled water leaving the plot. A stock tank was connected to the gutter with plastic pipe to store runoff. The stock tanks were covered by a plate in order to avoid direct entrance of rainfall.

Group 1 plots were at the initial stage of revegetation and had been abandoned for 8 yr. Group 2 and Group 3 plots had been revegetated for $25 \mathrm{yr}$. The vegetation of Group 1 plots was sparse apricot (Armeniaca vulgaris) planted in rows at interval distances of 2.5 or $5 \mathrm{~m}$. Patchy biological crusts covered most of the soil surface of plots in Group 1. Dense native shrubs (Spiraea pubescens Turcz.) with an arborous layer of sparse artificial (acacia) covered plots of Group 2. Plots of Group 3 were dominated by dense tussock (A. scoparia) and beard grass (Andropogon L.). Liu et al. (2012) used a digital camera (Finepix S1000, Fujifilm) and a $50 \times 50 \mathrm{~cm}$ subplot mesh to perpendicularly photograph the surface of each runoff plot. The resulting images were transferred to digital vegetation cover maps in ArcMap. The vegetation cover ratio of each runoff plot could be easily obtained from these maps. Table 1 shows the main characteristics of each runoff plot.

Twenty-seven samples of topsoil $(0-10 \mathrm{~cm})$ were collected from each plot group. Soil texture was analyzed using a Mastersizer 2000 particle analyser (Malvern Instruments Ltd., Worcestershire, UK). Bulk density (BD), total Kjeldahl nitrogen (TN), total carbon (TC), total phosphorous (TP), soil organic carbon (SOC), electrical conductivity (EC) and $\mathrm{pH}$ 
Table 1. Main characteristics of each runoff plot in the three groups.

\begin{tabular}{|c|c|c|c|c|c|c|c|c|c|}
\hline & \multicolumn{3}{|c|}{ Group 1} & \multicolumn{3}{|c|}{ Group 2} & \multicolumn{3}{|c|}{ Group 3} \\
\hline & Plot 11 & Plot 12 & Plot 13 & Plot 21 & Plot 22 & Plot 23 & Plot 31 & Plot 32 & Plot 33 \\
\hline Length (m) & 5 & 9 & 13 & 5 & 9 & 13 & 5 & 9 & 13 \\
\hline Width (m) & 2 & 2 & 2 & 2 & 2 & 2 & 2 & 2 & 2 \\
\hline Slope gradient $\left(^{\circ}\right)$ & 19 & 19 & 19 & 25 & 25 & 25 & 21 & 22 & 23.5 \\
\hline Revegetation time (yr) & 8 & 8 & 8 & 25 & 25 & 25 & 25 & 25 & 25 \\
\hline Main vegetation type & \multicolumn{3}{|c|}{ Armeniaca vulgaris } & \multicolumn{3}{|c|}{ Spiraea pubescens Turcz. } & \multicolumn{3}{|c|}{ A. scoparia, Andropogon L. } \\
\hline Vegetation cover $(\%)$ & 40.6 & 54.8 & 29.0 & 76.5 & 71.5 & 72.5 & 71.2 & 71.6 & 89.1 \\
\hline Hydrologic condition & Fair & Fair & Poor & Good & Good & Good & Good & Good & Good \\
\hline $\mathrm{CN}_{\text {II }}$ value & 58 & 58 & 73 & 68 & 68 & 68 & 62 & 62 & 62 \\
\hline
\end{tabular}

were tested using standard soil testing methods (Liu et al., 1996). Soil properties of each runoff plot group are shown in Table 2.

Rainfall, runoff and erosion of the nine runoff plots were monitored during the rainy season in 2008, 2009, 2010 and 2011. Rainfall depth was measured with an accuracy of $0.2 \mathrm{~mm}$ using a tipping bucket rain gauge that was connected to a data logger. The runoff mixed with the sediment discharged from each plot was collected after each rainfall event, and the volume was measured. After settling for $24 \mathrm{~h}$, sediment was separated from water. Sediment from the gutters was also collected and added to the stock tank sediment since this was also output from the plot. The collected sediment was first air-dried for more than $24 \mathrm{~h}$, and dried in an oven at a temperature of $105^{\circ} \mathrm{C}$ for longer than $8 \mathrm{~h}$ until constant weight was achieved. Calculations of runoff in $\mathrm{mm}$ and erosion rate in tha ${ }^{-1}$ were obtained for each event. In total, there were 21 and 16 rainfall events that produced runoff and sediment, respectively. Table 3 provided the statistical characteristics of the rainfall for the simulated runoff events. The largest rainfall event occurred on 15 June 2008 with rainfall depth of $76.4 \mathrm{~mm}$, and the most intensive storm was on 25 August 2009 with rainfall intensity of $30.72 \mathrm{~mm} \mathrm{~h}^{-1}$. The largest $I_{30}$ reached $52.8 \mathrm{~mm} \mathrm{~h}^{-1}$ on 28 June 2008 , and the rainfall event on 19 July 2009 had the largest $P_{5}(79.6 \mathrm{~mm})$.

It is generally accepted that different erosive mechanisms can be expected in plots with different lengths. In particular, occurrence of interrill erosion alone can be presumed for the short plots, whereas both rill and interrill processes are expected on longest plots. In this study, the erosion status was observed at the end of each erosive event. There was only little rill generated in Plot 13 as it had the longest length and smallest vegetation cover. Sheet or interrill erosion dominated in the other runoff plots. Therefore, the effect of specific erosion processes on soil loss can be ignored in the soil loss simulation.
Table 2. Soil properties of the three runoff plot groups.

\begin{tabular}{lrrr}
\hline & Group 1 & Group 2 & Group 3 \\
\hline Sand (\%) & 22.83 & 24.40 & 24.39 \\
Silt $(\%)$ & 72.96 & 71.25 & 71.10 \\
Clay $(\%)$ & 4.21 & 4.36 & 4.5 \\
BD $\left(\mathrm{g} \mathrm{cm}^{-3}\right)$ & 1.04 & 1.30 & 1.17 \\
TN $(\%)$ & 0.06 & 0.12 & 0.10 \\
TC $(\%)$ & 1.91 & 2.53 & 2.22 \\
SOC $\left(\mathrm{g} \mathrm{kg}^{-1}\right)$ & 7.41 & 16.44 & 20.05 \\
TP $\left(\mathrm{g} \mathrm{kg}^{-1}\right)$ & 0.61 & 0.65 & 0.62 \\
pH & 8.42 & 8.28 & 8.32 \\
EC $\left(\mu \mathrm{s} \mathrm{cm}^{-1}\right)$ & 133.03 & 153.80 & 139.00 \\
\hline
\end{tabular}

* BD: bulk density

Table 3. Statistical characteristics of rainfall for the simulated runoff events.

\begin{tabular}{lrrrr}
\hline & $\begin{array}{r}\text { Rainfall } \\
\text { depth }(\mathrm{mm})\end{array}$ & $\begin{array}{r}\text { Rainfall intensity } \\
\left(\mathrm{mm} \mathrm{h}^{-1}\right)\end{array}$ & $\begin{array}{r}I_{30}^{\mathrm{a}} \\
\left(\mathrm{mm} \mathrm{h}^{-1}\right)\end{array}$ & $\begin{array}{r}P_{5}^{\mathrm{b}} \\
(\mathrm{mm})\end{array}$ \\
\hline Mean & 38.46 & 5.32 & 22.32 & 22.75 \\
Max & 76.40 & 30.72 & 52.80 & 79.60 \\
Min & 15.80 & 1.52 & 2.76 & 0.00 \\
SD & 18.52 & 6.30 & 17.08 & 25.73 \\
\hline
\end{tabular}

${ }^{a} I_{30}$ : maximum $30-m i n$ intensity during the event.

b $P_{5}$ : 5-day antecedent precipitation.

\subsection{Determination of model parameters}

\subsubsection{Parameters for rainfall-runoff modeling}

There are two parameters in the original or modified SCS$\mathrm{CN}$ model. One is the initial abstraction coefficient $\lambda$, and the other is the curve number $\mathrm{CN}$. $\lambda$ was assumed to be equal to 0.2 in its original development. However, the assumption of $\lambda=0.2$ has frequently been questioned for its validity and applicability, invoking a critical examination of the $I_{\mathrm{a}}-S$ relationship for pragmatic applications (Pronce and Hawkins, 1996; Baltas et al., 2007). The initial abstraction 


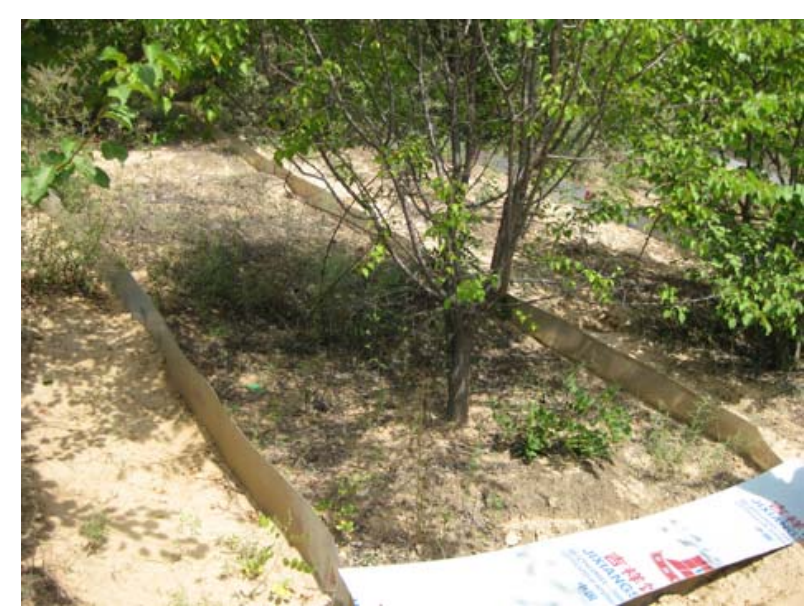

Group 1

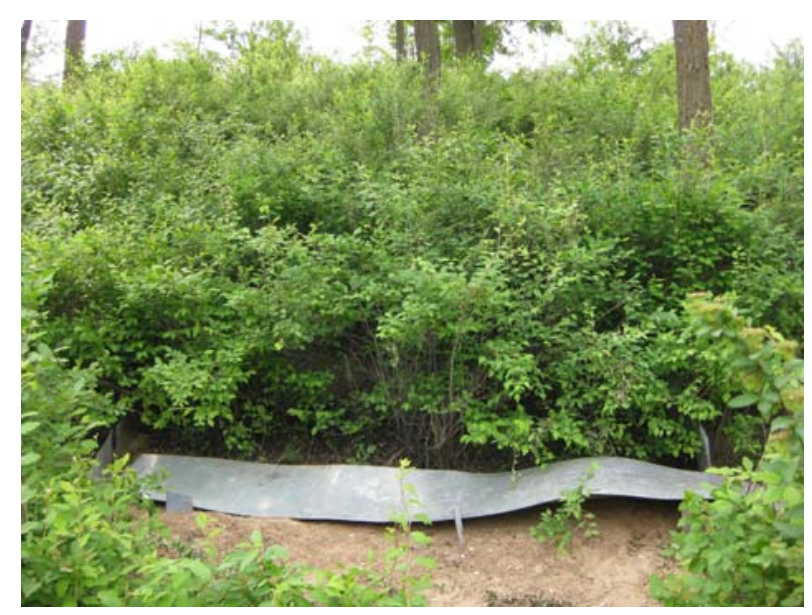

Group 2

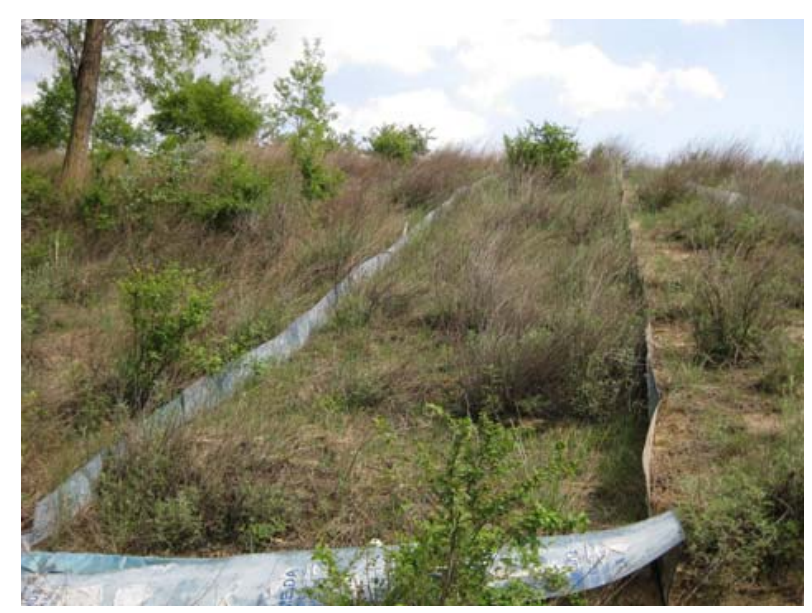

Group 3

Fig. 2. Pictures of runoff plot in the three groups. ratio represents the effects of soil and cover characteristics on the runoff process, and theoretically it is not a constant in different areas and for different rainfall events. It is generally accepted that the $\lambda$ value lies in the range of 0 to 0.3 . Mishra and Singh (1999) obtained values of $\lambda$ from 0 to 0.042 for three watersheds less than $1 \mathrm{~km}^{2}$ in the USA and for one $3124 \mathrm{~km}^{2}$ watershed located in India, respectively. Huang et al. (2007) optimized the $\lambda$ value to be 0.001 for four plots in the Loess Plateau. Fu et al. (2011) found that the prediction accuracy for $\lambda=0.05$ was greater than that for $\lambda=0.2 \mathrm{using}$ SCS-CN method to simulate plot runoff of 757 rainfall events in Zizhou and Xifeng cities located in the Loess Plateau of China. Similar results have been obtained from plots or watersheds in USA (Hawkins et al., 2002), semi-arid tropical highlands of northern Ethiopia (Descheemaeker et al., 2008) and the Three Gorges area of China (Shi et al., 2009). In this study, the value of $\lambda$ is not optimized using the measured rainfall-runoff data, as optimization of parameters cannot adequately examine the applicability of the modified SCS-CN model. Furthermore, the obtained optimization value is only reasonable for the studied plots, which limits the applications of the model in other areas. Therefore, the two commonly used values $(\lambda=0.05,0.2)$ are directly applied in the SCS$\mathrm{CN}$ model for comparison.

For the $\mathrm{CN}$ value, it needs the following steps to determine it with considering the effect of AMC, slope gradient and initial abstraction ratio. First, in terms of the hydrologic soil group (set to B) and hydrologic condition (determined by the measured vegetation cover), the $\mathrm{CN}_{\mathrm{II}}$ value for the normal AMC (AMC II) can be determined from USDA-NRCS handbook with land cover and hydrologic soil-cover complexes of each runoff plot (see runoff curve numbers for arid and semiarid ranges as shown in Table 9-2 of USDA-NRCS, 2004). The $\mathrm{CN}_{\mathrm{II}}$ value for each runoff plot is listed in Table 1 .

Second, the $\mathrm{CN}_{\text {II }}$ value obtained from the USDA-NRCS handbook corresponds to a slope of $5 \%$, and it should be adjusted to the actual slope. Huang et al. (2006) used SCS$\mathrm{CN}$ method to evaluate an 11-yr runoff plot experiment with slopes ranging from $14 \%$ to $140 \%$ in Xifeng city located in the Loess Plateau of China, and proposed the following equation to consider the effect of slope on $\mathrm{CN}_{\mathrm{II}}$ value:

$\mathrm{CN}_{\mathrm{II} \alpha}=\mathrm{CN}_{\mathrm{II}} \frac{322.79+15.63 \alpha}{\alpha+323.52}$

where $\mathrm{CN}_{\mathrm{II} \alpha}$ is the slope-adjusted $\mathrm{CN}_{\mathrm{II}}$ value, and $\alpha$ is the slope steepness (\%).

Third, the above-determined $\mathrm{CN}_{\mathrm{II} \alpha}$ value is the median $\mathrm{CN}$ value taken as a representative value for the AMC II condition. It should be converted to AMC I (dry) or AMC III (wet) condition depending on the magnitude of $P_{5}$ with the following relations (Hawkins et al., 1985):

$\mathrm{CN}_{\mathrm{I} \alpha}=\frac{\mathrm{CN}_{\mathrm{II} \alpha}}{2.281-0.0128 \mathrm{CN}_{\mathrm{II} \alpha}}$ 
$\mathrm{CN}_{\mathrm{III} \alpha}=\frac{\mathrm{CN}_{\mathrm{II} \alpha}}{0.427+0.00573 \mathrm{CN}_{\mathrm{II} \alpha}}$

where $\mathrm{CN}_{\mathrm{I} \alpha}$ and $\mathrm{CN}_{\text {III } \alpha}$ are the slope-adjusted $\mathrm{CN}$ values corresponding to the AMC I and AMC III condition, respectively.

Finally, if $\lambda=0.05$ is used in SCS-CN method, a new set of curve numbers must be developed (Hawkins et al., 2002). Hawkins et al. (2002) developed the following relationship that converted the 0.20 -based $\mathrm{CN}$ to 0.05 -based $\mathrm{CN}$ from model fitting results using rainfall-runoff data:

$$
\mathrm{CN}_{0.05}=\frac{100}{1.879\left[\frac{100}{\mathrm{CN}_{0.20}}-1\right]^{1.15}+1}
$$

$S_{0.05}=0.8187 S_{0.20}^{1.15}$

where $\mathrm{CN}_{0.05}$ and $S_{0.05}(\mathrm{~mm})$ are the $\mathrm{CN}$ and potential water storage values with $\lambda=0.05$, respectively, and $\mathrm{CN}_{0.20}$ and $S_{0.20}(\mathrm{~mm})$ are the values with $\lambda=0.2$.

\subsubsection{Parameters for soil loss modeling}

In the original or modified RUSLE model, the six erosivity factors are determined in the following. The event rainfall erosivity factor $\left(R_{\mathrm{e}}\right)$ is calculated as follows (Brown and Foster, 1987):

$R_{\mathrm{e}}=\mathrm{EI}_{30}=\left(\sum_{r=1}^{n}\left(e_{\mathrm{r}} v_{\mathrm{r}}\right)\right) I_{30}$

where $e_{\mathrm{r}}$ and $v_{\mathrm{r}}$ are the unit rainfall energy $\left(\mathrm{MJ} \mathrm{ha}^{-1} \mathrm{~mm}^{-1}\right.$ ) and the rainfall volume $(\mathrm{mm})$ during a time period $r$, respectively. The unit rainfall energy $\left(e_{\mathrm{r}}\right)$ is calculated for each time interval (Brown and Foster, 1987):

$e_{\mathrm{r}}=0.29\left[1-0.72 \exp \left(-0.05 i_{\mathrm{r}}\right)\right]$

where $i_{\mathrm{r}}$ is the rainfall intensity during the time interval ( $\mathrm{mm}$ $\left.\mathrm{h}^{-1}\right)$.

This study employs the method developed from EPIC by Sharply and Williams (1990) to estimate the soil erosivity $K$ factor. The calculation formula is as follows:

$K=\left\{0.2+0.3 \exp \left[-0.0256 S_{\mathrm{a}}\left(1-S_{i} / 100\right)\right]\right\}\left(\frac{S_{i}}{\mathrm{Cl}+S_{i}}\right)^{0.3}$

$\left[1-\frac{0.25 C}{C+\exp (3.72-2.95 C)}\right]\left[1-\frac{0.7 S_{n}}{S_{n}+\exp \left(-5.51+22.9 S_{n}\right)}\right]$

where $S_{\mathrm{a}}$ is the sand content (\%); $S_{i}$ is the silt content (\%); $\mathrm{Cl}$ is the clay content (\%); $C$ is the organic carbon content (\%); and $S_{n}=1-S_{\mathrm{a}} / 100$.
For each plot, a value of the topographic factor, $L S$, is calculated according to the following relationships (Nearing, 1997; Renard et al., 1997):

$$
\begin{aligned}
& L=\left(\frac{\lambda}{22.13}\right)^{m} \\
& S=-1.5+\frac{17}{1+\exp (2.3-6.1 \sin \beta)} \\
& m=\frac{F}{1+F} \\
& F=\frac{\sin \beta / 0.0896}{3(\sin \beta)^{0.8}+0.56}
\end{aligned}
$$

where $\lambda$ is the slope length $(m), m$ is the slope-length exponent, and $F$ is the ratio of rill erosion to interrill erosion which depends on the slope angle, $\beta\left(^{\circ}\right)$.

Vegetation type and vegetation cover play major roles in controlling soil loss, especially in the restoration lands of arid and semi-arid regions. Many experimental studies have verified that soil loss exponentially decreased with vegetation cover ratio for a specific vegetation type (Moreno-de las Heras et al., 2009; Bartley et al., 2010; Garcia-Estringana et al., 2010; Podwojewski et al., 2011). Based on numerous observed plot data in Ansai city located in the middle part of the Loess Plateau of China, Jiang et al. (1996) proposed the following exponential functions to describe the relationship between the cover-management $C$ factor and cover ratio of woodland and grassland:

$C_{\text {grassland }}=\exp \left[-0.0418\left(V_{\text {cover }}-5\right)\right]$

$C_{\text {woodland }}=\exp \left[-0.0085\left(V_{\text {cover }}-5\right)^{1.5}\right]$

where $C_{\text {grassland }}$ and $C_{\text {woodland }}$ are the cover-management factor of woodland and grassland, respectively, and $V_{\text {cover }}$ is vegetation cover (\%). The above relationships have also been verified by Zhang et al. (2003) with observation data from 33 plots with nine types of grassland and woodland in the Loess Plateau of China. In this study, Eqs. (27) and (28) are used to determine the $C$ factor of the nine plots. As there is no soil conservation practice for all the plots, the $P$ factor is set to be $1(P=1)$.

In the modified RUSLE model, there is no independent method to determine the introduced empirical coefficients $a$ and $b$. In this study, the observed event soil loss data from all plots in 2008 are fitted by the modified RUSLE model to determine $a$ and $b$. After model calibration, the modified RUSLE model is used to predict the event soil loss in the rest of three years $(2009,2010$ and 2011). 

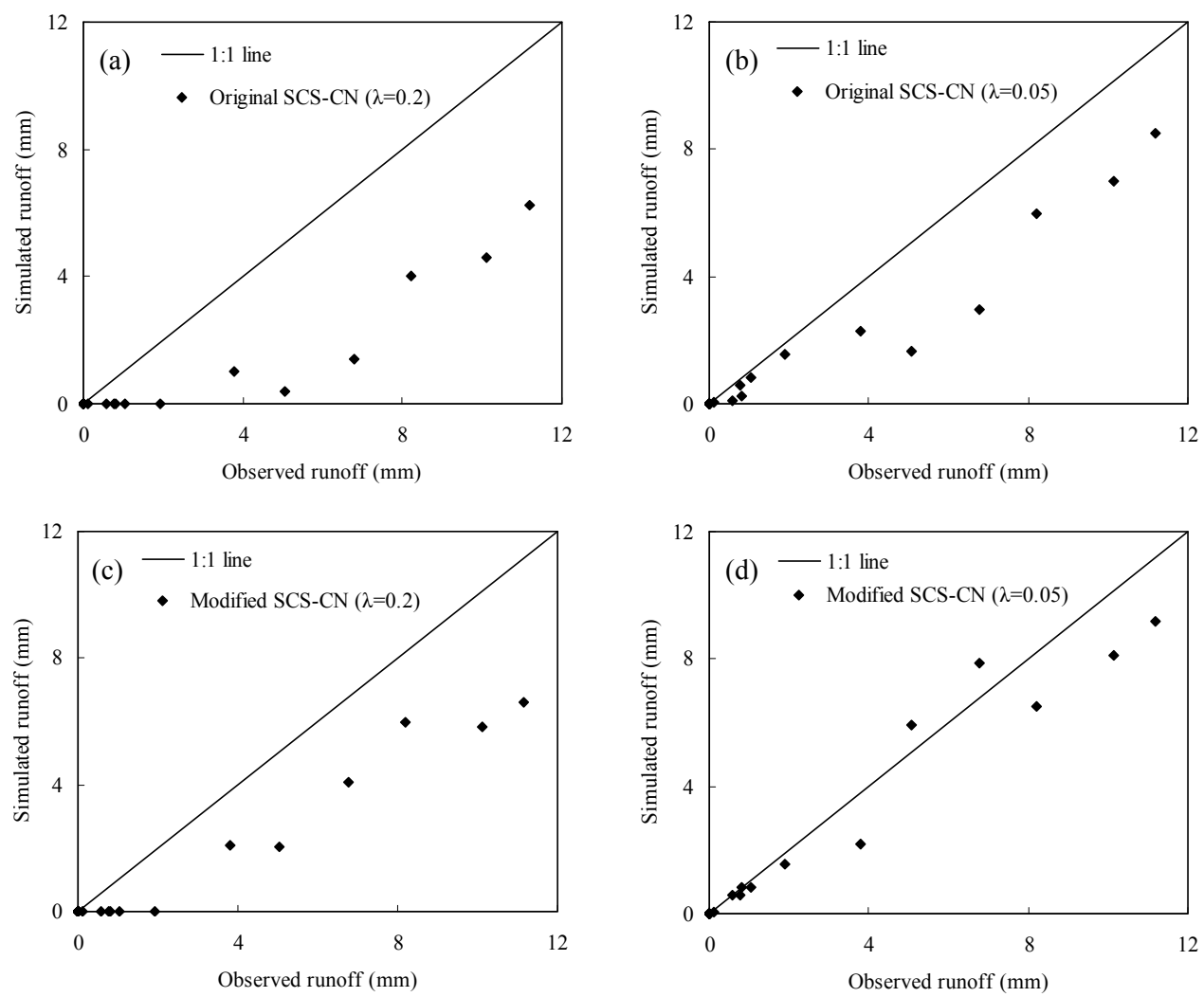

Fig. 3. Comparison between observed and predicted event runoff using (a) original SCS-CN $(\lambda=0.2)$, (b) original SCS-CN $(\lambda=0.05)$, (c) modified SCS-CN $(\lambda=0.2)$ and $(\mathbf{d})$ modified SCS-CN $(\lambda=0.05)$ models for Group 1 runoff plots.

\subsection{Model performance evaluation criteria}

In this study, the following four popular statistical criteria are used to measure the agreement between predicted and observed values of event runoff and soil loss. A good agreement indicates a good model performance, and vice versa.

$\mathrm{EF}=1-\frac{\sum_{i=1}^{N}\left(O_{i}-P_{i}\right)^{2}}{\sum_{i=1}^{N}\left(O_{i}-\bar{O}\right)^{2}}$

$\mathrm{RMSE}=\sqrt{\frac{1}{N} \sum_{i=1}^{N}\left(O_{i}-P_{i}\right)^{2}}$

$\mathrm{NRMSE}=\frac{\sqrt{\frac{1}{N} \sum_{i=1}^{N}\left(O_{i}-P_{i}\right)^{2}}}{\bar{O}}$

$e=\frac{1}{N} \sum_{i=1}^{N}\left(P_{i}-O_{i}\right)$ where EF is the Nash-Sutcliffe model efficiency, RMSE is the root-mean- square error, NRMSE is the normalized rootmean-square error, $e$ is the bias, $O_{i}$ and $P_{i}$ are the observed and predicted runoff or soil loss of the $i$-th rainfall event, respectively, $\bar{O}$ is the average observed runoff or soil loss, and $N$ is the total number of rainfall events that produce runoff or soil loss. $\mathrm{EF}=1$ indicates a perfect agreement between observed and predicted values, and its decreasing values indicate poor agreement. A higher RMSE or NRMSE value indicates poor model performance. Bias represents the average differences between the predicted and observed values.

\section{Results and discussion}

\subsection{Prediction results of event runoff}

There are four rainfall-runoff models including the original SCS-CN model $(\lambda=0.2)$, the original SCS-CN model $(\lambda=0.05)$, the modified SCS-CN model $(\lambda=0.2)$ and the modified SCS-CN model $(\lambda=0.05)$ to predict event runoff. Figures 3, 4 and 5 show the comparison between the observed and predicted event runoff of the Group 1, Group 2 and Group 3 plots, respectively. It should be noted that the runoff of each event in these figures is the average value of 

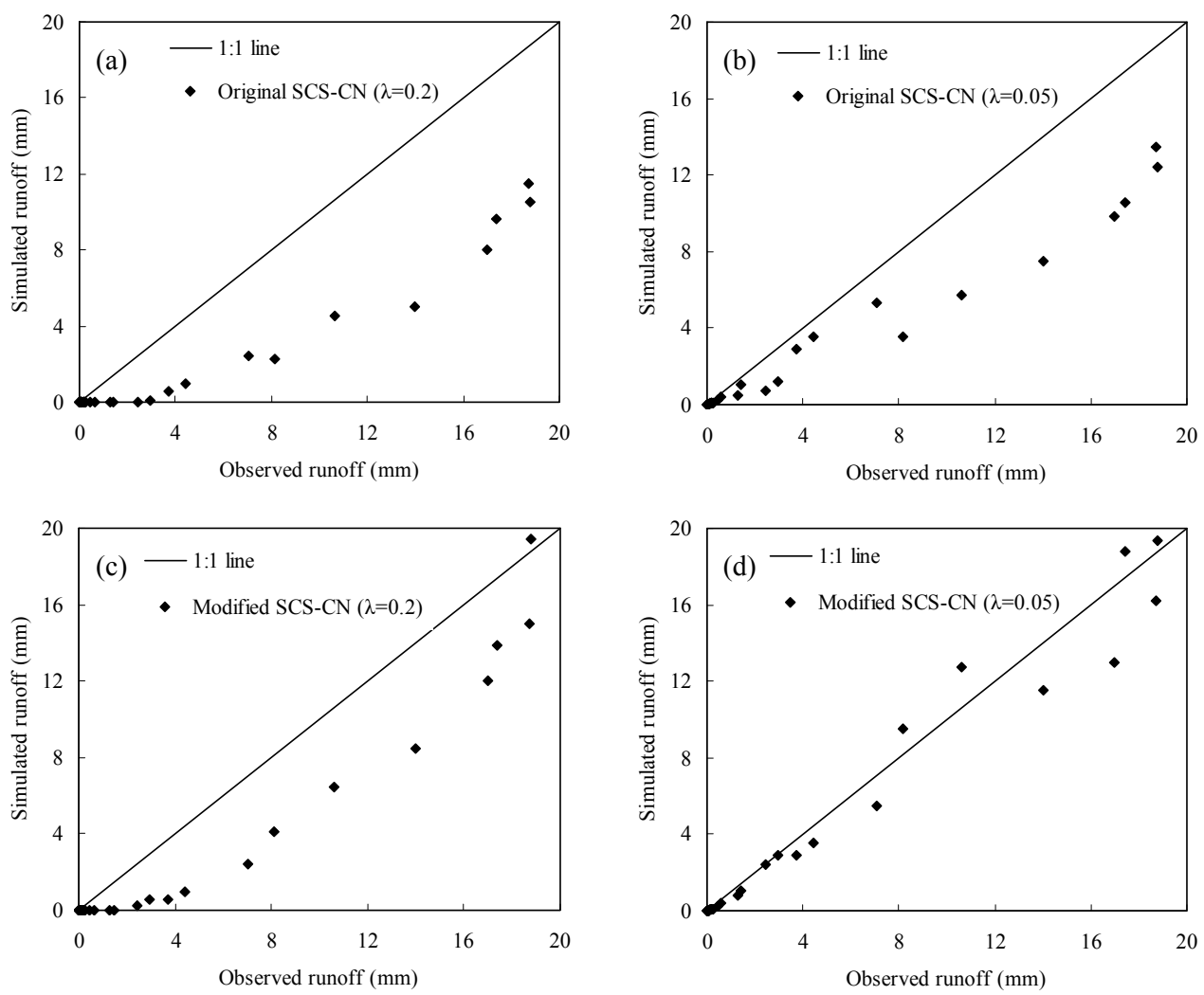

Fig. 4. Comparison between observed and predicted event runoff using (a) original SCS-CN $(\lambda=0.2)$, (b) original SCS-CN $(\lambda=0.05)$, (c) modified SCS-CN $(\lambda=0.2)$ and $(\mathbf{d})$ modified SCS-CN $(\lambda=0.05)$ models for Group 2 runoff plots.

the three plots that belonged to the same group, because the SCS-CN model cannot take the effect of plot length into account. The original SCS-CN model $(\lambda=0.2)$ significantly underestimates the observed runoff (Figs. 3a, 4a and 5a). There are many rainfall events that produce small runoff, but the simulation results of the original SCS-CN model $(\lambda=0.2)$ for these events are almost equal to 0 . The original SCS-CN model $(\lambda=0.05)$ predicts the low event runoff well, but it underestimates the high event runoff, especially for the rainfall events that have large $P_{5}$ (Figs. $3 \mathrm{~b}, 4 \mathrm{~b}$ and $5 \mathrm{~b}$ ). Although the predicted runoff of large rainfall events by the modified SCS-CN model $(\lambda=0.2)$ is closer to the observed results compared to the original SCS-CN model $(\lambda=0.2$ or $0.05)$, the modified SCS-CN model $(\lambda=0.2)$ still underestimates the high event runoff (Figs. $3 c, 4 c$ and $5 c$ ). Furthermore, it does not predict runoff for the small rainfall event, which is similar to the original SCS-CN model $(\lambda=0.2)$. Compared to the above three models, the prediction results of the modified SCS-CN model $(\lambda=0.05)$ are consistent with the observations, having a ratio close to $1: 1$, as shown in Figs. $3 \mathrm{~d}, 4 \mathrm{~d}$ and $5 \mathrm{~d}$. This result indicates that the modified SCS-CN model $(\lambda=0.05)$ predicts both the small and large event runoff well.

The AMCs of the observed 21 rainfall-runoff events are determined based on the amount of $P_{5}$. Only four rain- fall events have normal soil moisture conditions (AMC II, $36 \mathrm{~mm}<P_{5}<53 \mathrm{~mm}$ ). Thirteen rainfall events have the AMC I conditions $\left(P_{5}<36 \mathrm{~mm}\right)$, and four rainfall events have the AMC III conditions $\left(P_{5}>53 \mathrm{~mm}\right)$. The observed results (not shown here) indicate that most of the rainfall events with AMC I condition produce small or no runoff, whereas those with AMC II and AMC III conditions result in significant runoff. As shown in Figs. 3, 4 and 5, the original SCS-CN models underestimate the observed event runoff, especially those with AMC II and AMC III conditions, although the original SCS-CN model $(\lambda=0.05)$ can well predict the runoff events with AMC I condition. Compared to them, the simulation results of the modified SCS-CN models are closer to the observed event runoff with AMC II and AMC III conditions, especially in that the modified SCS$\mathrm{CN}$ model $(\lambda=0.05)$ can adequately describe almost all the runoff events. The above results indicate that the AMC plays a significant role in rainfall-runoff production and estimation, and the modified SCS-CN model $(\lambda=0.05)$ can account for most of the AMC conditions.

Table 4 compares the evaluation criteria of event runoff prediction performance of the four models. The prediction results of modified SCS-CN model $(\lambda=0.05)$ provide a greater model efficiency (EF) and a lower RMSE, NRMSE and bias than the original SCS-CN model $(\lambda=0.2$ or 0.05$)$ 

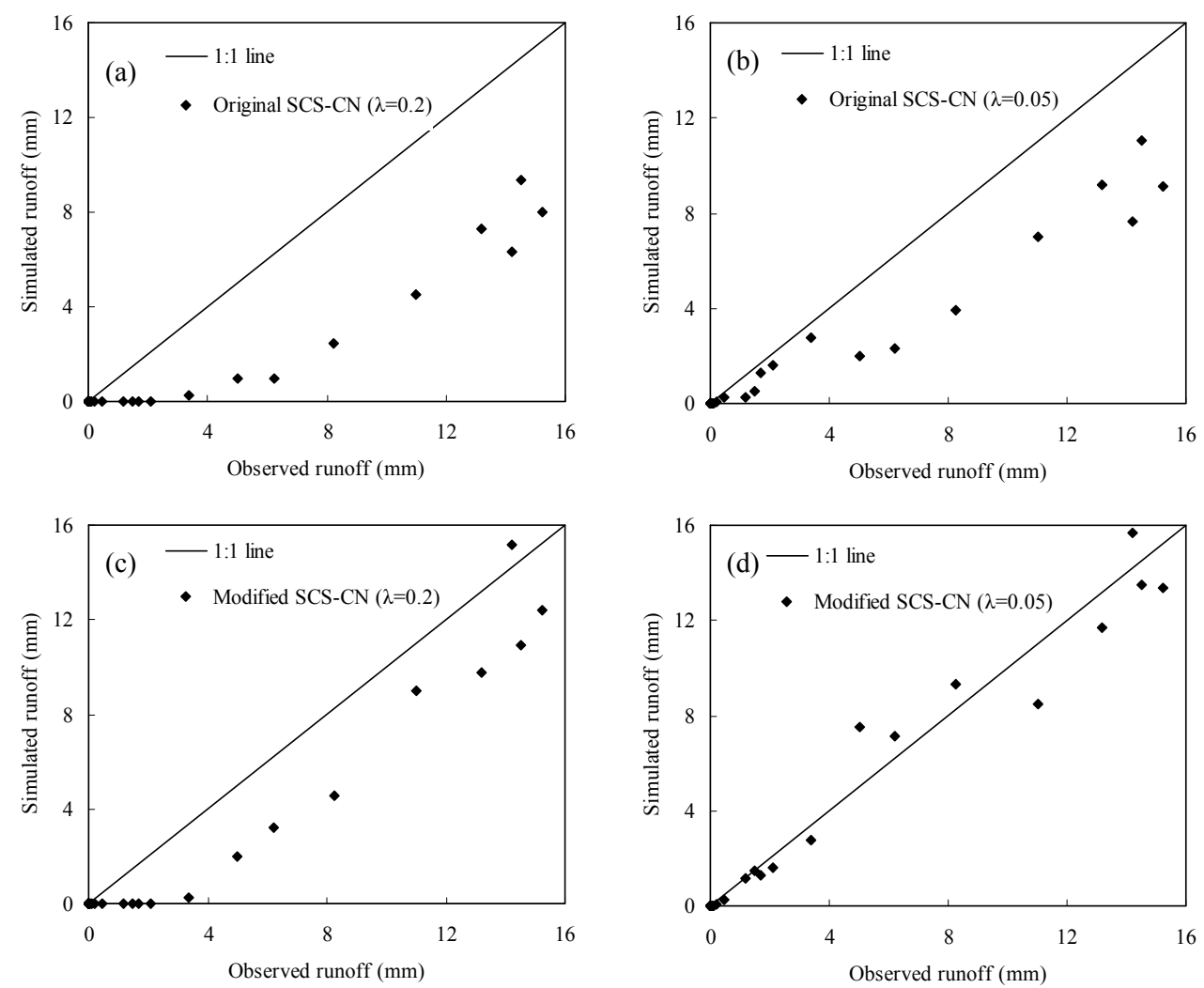

Fig. 5. Comparison between observed and predicted event runoff using (a) original SCS-CN $(\lambda=0.2)$, (b) original SCS-CN $(\lambda=0.05)$, (c) modified SCS-CN $(\lambda=0.2)$ and $(\mathbf{d})$ modified SCS-CN $(\lambda=0.05)$ models for Group 3 runoff plots.

and the modified SCS-CN model $(\lambda=0.2)$ do. The EF values of the modified SCS-CN model $(\lambda=0.05)$ are 0.899 for Group 1 plot, 0.892 for Group 2 plot, and 0.879 for Group 3 plot. The bias values of the other three models are negative (most of them are less than $-1 \mathrm{~mm}$; see Table 4 ), indicating that these three models substantially underestimate the event runoff, as shown from Figs. 3, 4 and 5. The above comparison results of the model performance evaluation criteria further prove the advantages of the modified SCS-CN model $(\lambda=0.05)$ over the other three models.

The simulated efficiency of the modified SCS-CN model is also compared with other studies that used the SCS-CN method to simulate event plot runoff in the Loess Plateau. Fu et al. (2011) used SCS-CN with $\lambda=0.05$ to simulate runoff from farmland plots in Zizhou (205 rainfall events) and Xifeng (552 rainfall events) experiment stations, and the EF values were only 0.25 and 0.51 , respectively. Huang et al. (2006) reported a EF value of 0.826 for the pasture and alfalfa plots in Xifeng, which was used in the $\mathrm{CN}$ equation (Eq. 15) to simulate runoff. The EF value of the SCS-CN method in which the $\mathrm{CN}$ value was a non-linear equation of surface soil moisture was 0.779 in the city of Suide (Huang et al., 2007). It should be noted that the parameters of the nonlinear equation and $\lambda$ in Huang et al. (2007) were determined by optimization, whereas in this study all the parameters in the SCS-CN model were independently determined. The efficiency of the modified SCS-CN model $(\lambda=0.05)$ is better than other forms of SCS-CN method in the above-mentioned studies conducted by other researches, as both the effects of antecedent moisture condition and slope gradient are explicitly considered in the modified SCS-CN model.

\subsection{Prediction results of event soil loss}

The simulated event soil losses of the three runoff plot groups in 2008 are compared with the measurements for calibration of the modified RUSLE model (Fig. 6). The estimated values of the empirical coefficients $a$ and $b$ in the modified RUSLE model are 1.723 and 1.548 , respectively. The $a$ value lies in the range of the ratio between the soil erodibility of the USLE-M and USLE (1.40-3.87) obtained by Kinnell and Risse (1998). Furthermore, as noted by Bagarello et al. (2010), after using an exponent of the event rainfallrunoff erosivity $\left(Q_{\mathrm{R}} \mathrm{EI}_{30}\right)$ term in the soil loss model, the calculated soil erodibility factor is representative of an intrinsic soil property. The $b$ value is close to what Bagarello et al. (2010) obtained in Italy on bare plots varying in length from 11 to $44 \mathrm{~m}$ (1.47). The above results indicate that the obtained coefficients have robust physical meanings, and they 
Table 4. Values of model performance evaluation criteria to predict event runoff of the three runoff plot groups

\begin{tabular}{llrrrr}
\hline Plot type & Model & EF & $\begin{array}{r}\text { RMSE } \\
(\mathrm{mm})\end{array}$ & $\begin{array}{r}\text { NRMSE } \\
(\mathrm{mm})\end{array}$ & $\begin{array}{r}e \\
(\mathrm{~mm})\end{array}$ \\
\hline \multirow{5}{*}{ Group 1 } & Original SCS-CN $(\lambda=0.2)$ & 0.545 & 2.116 & 1.378 & -1.030 \\
& Original SCS-CN $(\lambda=0.05)$ & 0.697 & 1.578 & 1.028 & -0.794 \\
& Modified SCS-CN $(\lambda=0.2)$ & 0.642 & 1.833 & 1.163 & -0.898 \\
& Modified SCS-CN $(\lambda=0.05)$ & 0.899 & 0.838 & 0.616 & -0.115 \\
\hline \multirow{5}{*}{ Group 2 } & Original SCS-CN $(\lambda=0.2)$ & 0.591 & 3.288 & 0.862 & -2.094 \\
& Original SCS-CN $(\lambda=0.05)$ & 0.672 & 2.561 & 0.672 & -1.427 \\
& Modified SCS-CN $(\lambda=0.2)$ & 0.719 & 2.141 & 0.561 & -1.372 \\
& Modified SCS-CN $(\lambda=0.05)$ & 0.892 & 0.859 & 0.325 & -0.209 \\
\hline \multirow{5}{*}{ Group 3 } & Original SCS-CN $(\lambda=0.2)$ & 0.559 & 3.095 & 1.016 & -1.763 \\
& Original SCS-CN $(\lambda=0.05)$ & 0.709 & 2.318 & 0.761 & -1.192 \\
& Modified SCS-CN $(\lambda=0.2)$ & 0.732 & 1.688 & 0.554 & -0.960 \\
& Modified SCS-CN $(\lambda=0.05)$ & 0.879 & 0.86 & 0.317 & -0.202 \\
\hline
\end{tabular}

reflect the impact of changing the event rainfall erosivity factor on soil erodibility. Figure 6 shows that the simulated event soil loss agrees well with the measured values. The EF, RMSE, NRMSE and $e$ values of modified RUSLE model simulation results are $0.810,0.163 \mathrm{tha}^{-1}, 0.231 \mathrm{tha}^{-1}$ and $0.033 \mathrm{tha}^{-1}$, respectively. This again reflects the fact that the modified RUSLE model is well calibrated.

Figures 7, 8 and 9 show the comparison between the observed and predicted event soil loss of the Group 1, Group 2 and Group 3 runoff plots during the rainy season of 20092011. The predicted event soil loss of the original RUSLE model is significantly different from the observed ones. In general, the original RUSLE model overestimates low event soil losses and underestimates high event soil losses (Figs. 7a, 8a and 9a), which have also been indicated by Kinnell $(2005,2007,2010)$. With respect to the original RUSLE model, the predicting results of the modified RUSLE model are more satisfactory (Figs. $7 \mathrm{~b}, 8 \mathrm{~b}$ and $9 \mathrm{~b}$ ). The better performance of the modified RUSLE model is also supported by its larger EF and smaller RMSE, NRMSE and $e$ values than those of the original RUSLE model, as shown in Table 5. The EF values of the modified RUSLE model are over 0.70 , whereas those of the original RUSLE are only about 0.30 .

Besides using the estimated $Q_{\mathrm{R}}$ from the modified SCS$\mathrm{CN}$ model, we also used Eq. (14) with the measured runoff ratio to simulate the event soil loss. This is necessary to separately establish the approximations from the modified RUSLE model's structure and from the unavoidable uncertainties associated with runoff estimation. The EF values of the modified RUSLE model with measured runoff ratio for Group 1, Group 2 and Group 3 runoff plots are $0.816,0.865$ and 0.847 , respectively. The performance of the modified RUSLE model with the measured runoff ratio improves to some degree compared to that with the estimated runoff ratio. Furthermore, with the measured runoff ratio, the mod-

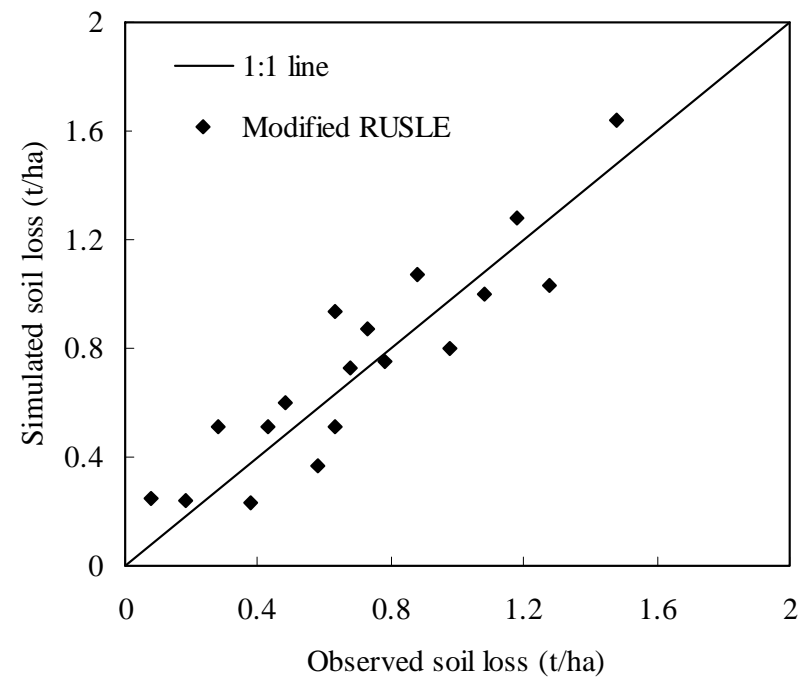

Fig. 6. Comparison between observed and simulated event soil loss using observed data of the three runoff plot groups in 2008 to calibrate the modified RUSLE model.

ified RUSLE model can better account for observed variations in sediment yield of plots with different lengths. This result indicates that including runoff coefficient in the erosivity term is the base for the satisfactory performance of the modified RUSLE model, and that developing procedures for accurately estimating the runoff coefficient is desirable, as it can further improve the soil loss prediction and has practical importance.

\subsection{Physical interpretation of model performance}

The substantial underestimation of event runoff by the original SCS-CN model $(\lambda=0.2)$ is due to the fact that it overestimates the initial abstraction with $\lambda=0.2$ and does not 
Table 5. Values of model performance evaluation criteria to predict event soil loss of the three runoff plot groups.

\begin{tabular}{llrrrr}
\hline Plot type & Model & EF & $\begin{array}{r}\text { RMSE } \\
\left(\mathrm{tha}^{-1}\right)\end{array}$ & $\begin{array}{r}\text { NRMSE } \\
\left(\mathrm{t} \mathrm{ha}^{-1}\right)\end{array}$ & $\begin{array}{r}e \\
\left(\mathrm{t} \mathrm{ha}^{-1}\right)\end{array}$ \\
\hline \multirow{2}{*}{ Group 1 } & Original RUSLE & 0.272 & 0.302 & 0.533 & 0.102 \\
& Modified RUSLE & 0.704 & 0.192 & 0.339 & 0.050 \\
\hline \multirow{2}{*}{ Group 2 } & Original RUSLE & 0.331 & 0.330 & 0.430 & 0.036 \\
& Modified RUSLE & 0.746 & 0.203 & 0.265 & -0.010 \\
\hline \multirow{2}{*}{ Group 3 } & Original RUSLE & 0.373 & 0.347 & 0.409 & 0.022 \\
& Modified RUSLE & 0.743 & 0.222 & 0.262 & 0.012 \\
\hline
\end{tabular}
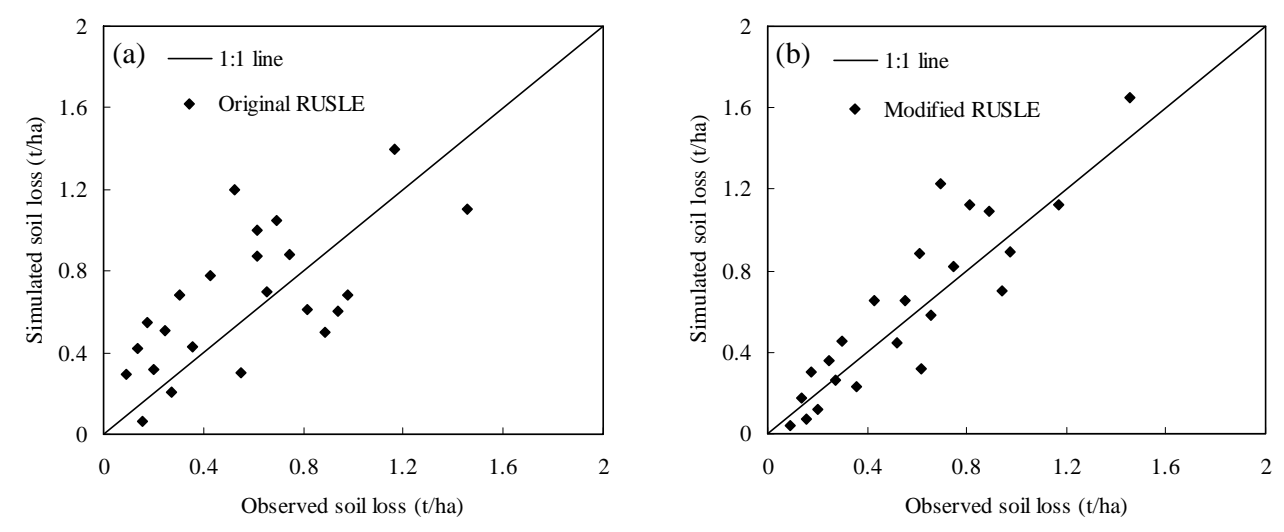

Fig. 7. Comparison between observed and predicted event soil loss during 2009-2011 using (a) original RUSLE and (b) modified RUSLE models for Group 1 runoff plots.

explicitly consider the effect of antecedent moisture amount in soil on production of runoff. For the rainfall events that have large $P_{5}$, there is a considerable amount of water in the soil before the start of rainstorm, which can reduce infiltration and enhance runoff, whereas the original SCS-CN model assumes that the soil is complete dry (Eq. 2), and the effect of antecedent moisture is ignored. Therefore, even though the initial abstraction can be reasonably estimated with $\lambda=0.05$, the original SCS-CN model can only predict the low event runoff accurately with small or no antecedent moisture, and still underestimates the event runoff produced by the rainfall events that have large $P_{5}$. After consideration of the antecedent moisture, the prediction performance of modified SCS-CN model substantially improves with $\lambda=0.05$, but there are still considerable errors for the modified SCS-CN model with $\lambda=0.2$. Therefore, the antecedent moisture should be directly incorporated into the SCS-CN model (Eq. 6) and $\lambda=0.05$ is suitable for the initial abstraction coefficient in the study area. Combined effects of the above two factors result in the good performance of the modified SCS-CN model $(\lambda=0.05)$ compared to the other three models.

In rainfall erosion, soil particle detachment is caused by raindrops impacting the soil surface and by flow shear. Sediment downslope transport is mainly driven by the interaction between raindrop impact and flow (raindrop-induced saltation and rolling) or by flow alone (flow-driven saltation and rolling) (Kinnell, 2010). Therefore, rainfall drives the start of the soil loss, but both the rainfall and the runoff play an important role in producing sediment yield across the downslope boundary of an area. Although empirical relationships tend to exist between runoff amount and $E$, and between peak runoff rate and $I_{30}$, this implicit embedding through the $\mathrm{EI}_{30}$ index in the original RUSLE model cannot deal with the effect of runoff on soil loss and the response of soil loss to changes in the initial soil moisture status (Kinnell, 2010). This accounts for the failure of the original RUSLE model to reasonably predict event soil loss. The detailed reason for overestimation of low event soil losses and the underestimation of high event soil loss by the original RUSLE model needs further investigation.

The better performance of the modified RUSLE model is caused by two reasons. Firstly, the effect of runoff is directly considered in the modified RUSLE model through the rainfall-runoff erosivity index (Eq. 14). Secondly, the prediction accuracy level of event runoff achieved by the modified SCS-CN model $(\lambda=0.05)$ is sufficient, which ensures the ability of $Q_{\mathrm{R}} \mathrm{EI}_{30}$ index to predict event erosion. Moreover, as indicated by Kinnell (2010), including direct consideration of runoff in the event rainfall-runoff factor enhances the 

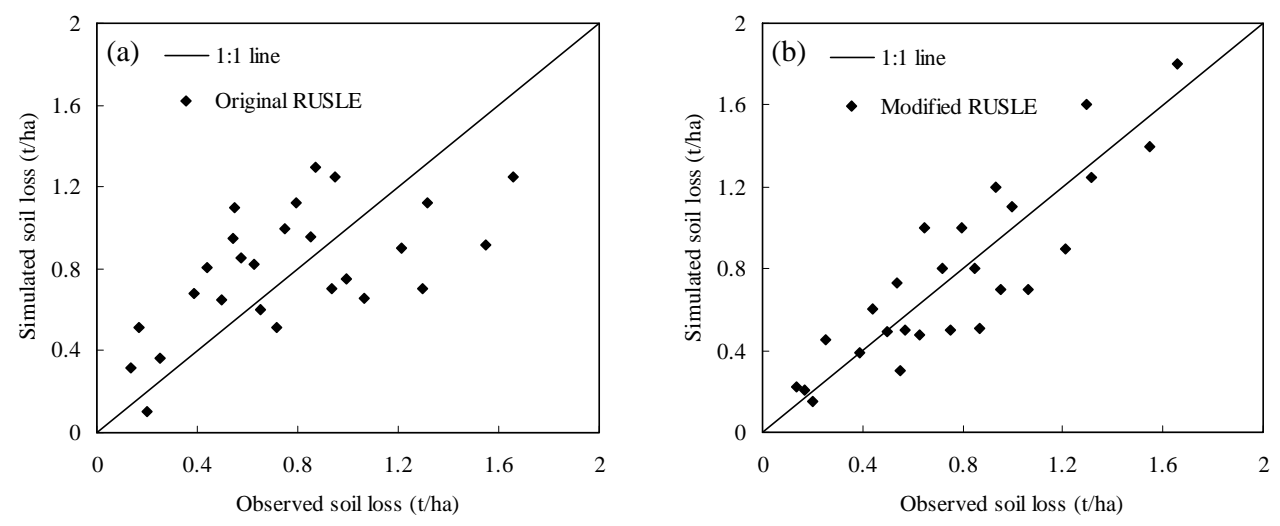

Fig. 8. Comparison between observed and predicted event soil loss during 2009-2011 using (a) original RUSLE and (b) modified RUSLE models for Group 2 runoff plots.
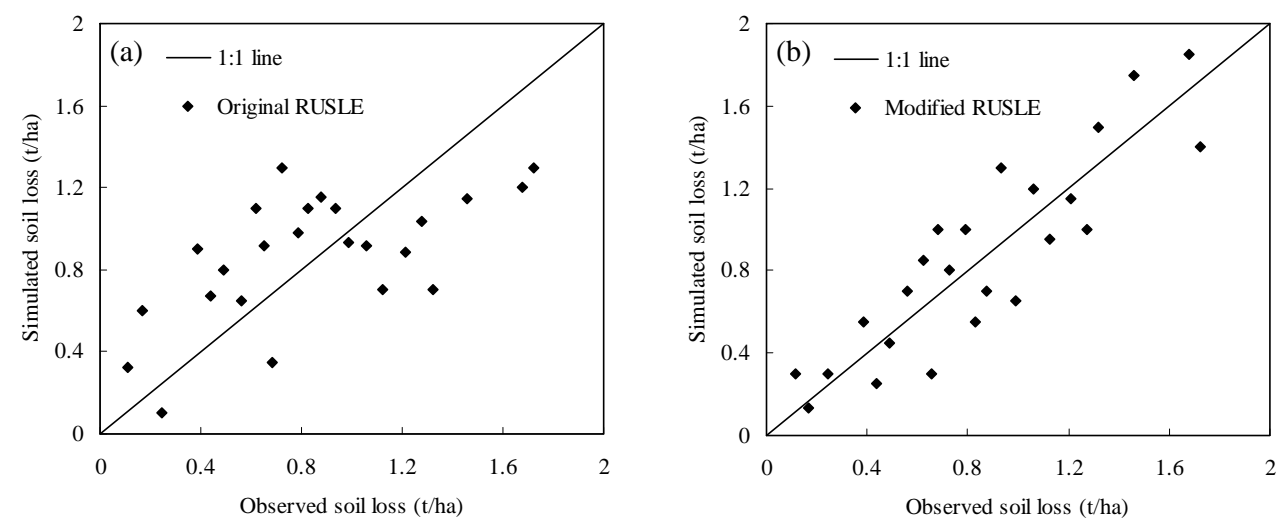

Fig. 9. Comparison between observed and predicted event soil loss during 2009-2011 using (a) original RUSLE and (b) modified RUSLE models for Group 3 runoff plots.

ability of the modified RUSLE model to account for variations in event soil loss. It may also improve the potential of the model to react to spatial variations in runoff and soil loss that resulted from spatial variations in soil and vegetation (Kinnell, 2010).

\subsection{Discussion of the proposed approach}

The proposed approach in this study coupled the modified SCS-CN and RUSLE models to link the rainfall-runofferosion modeling. It has the following advantages. Firstly, it substantially incorporates AMC in runoff production and directly considers runoff in soil loss to overcome the major disadvantage of the traditional SCS-CN and RUSLE models. Secondly, main stand and vegetation conditions of runoff plot (e.g. soil property, plot scale, plot slope, vegetation type, and vegetation cover), which are critical to runoff and soil loss, are explicitly incorporated into the model parameters. Thirdly, compared to models such as WEPP and EUOSEM, the proposed approach is straightforward, and almost all of the parameters (only empirical coefficients $a$ and $b$ in the modified RUSLE model are optimized) can be independently determined from observations without using measured rainfall-runoff and soil loss data. Finally, it accurately predicts event runoff and soil loss of different type of restoring vegetation in the Loess Plateau, which has complex geographical and climatic conditions. Results with reasonable accuracy could be expected in other regions. These advantages ensure that the proposed approach is useful for general applications. However, the approach still has its limitations.

Firstly, the physical base of determining antecedent moisture amount with $P_{5}$ is not robust and clear (Michel et al., 2005; Sahu et al., 2010), and it is not adequate to represent antecedent moisture condition only by the antecedent rainfall (Ali and Roy, 2010). In this study, the $P_{5}$ was used as an indicator of the antecedent soil moisture conditions. It was employed both for $M$ estimation (Eq. 9) and for modulating the $\mathrm{CN}_{\mathrm{I}}$ and $\mathrm{CN}_{\mathrm{III}}$ values (Eqs. 16 and 17). In this way, AMCs were updated continuously in runoff calculation through Eqs. (7) and (9), but with sudden jumps in the values of $\mathrm{CN}$ parameter. 
Many studies have compared the use of in situ (and modeled) soil moisture observations with the other indices based on antecedent rainfall, baseflow and groundwater table for the estimation of $S$ (Brocca et al., 2009a; Tramblay et al., 2010, 2011; Coustau et al., 2012). Additionally, satellitederived soil moisture observations have been employed for this purpose (Brocca et al., 2009b, 2011b; Beck et al., 2010). In all of these studies, the common aspect is that actual soil moisture, especially the moisture of surface soil layer, is the best indicator of soil moisture conditions and is more correlated with the $S$ or CN parameters of the SCS-CN model than antecedent precipitation (Huang et al., 2007; Tramblay et al., 2010). Therefore, it is necessary to estimate $S$ or CN values continuously to allow representation of varying soil moisture conditions. Huang et al. (2007) proposed a non-linear equation between the measured $\mathrm{CN}$ values and soil moisture values in the top $15 \mathrm{~cm}$ of soil in the runoff plots of the Loess Plateau, China. Brocca et al. (2009a) incorporated actual soil moisture observation for the direct estimation of the $S$ parameter by assuming a simple linear relationship in Central Italy, which has also been used in a continuous rainfall-runoff model to obtain a low parameterized but reliable modeling tool aimed at flood simulation (Brocca et al., 2010, 2011a). Unfortunately, because the soil moisture data are not available from the field experiment to directly determine $S$ or $\mathrm{CN}$ values, it is difficult to incorporate the above approach into the modified SCS-CN model in this study.

Secondly, the developed models are unable to account for plot-scale effects of runoff and soil loss, and its applicability should be further verified at long plots. For runoff simulation, the SCS-CN model was originally proposed for catchmentscale hydrologic modeling. Although it has been applied at plot scale (Shen et al., 2003; Huang et al., 2006, 2007; Fu et al., 2011), the suitability of using data collected at relatively short plots (not longer than $13 \mathrm{~m}$ in this study) to check the applicability of the SCS-CN model needs further investigation. Furthermore, the study of Liu et al. (2012) indicated that the runoff coefficient increased with plot length in Group 1 plots, while it decreased with increasing plot length in Group 2 and Group 3 plots. There is also some evidence that runoff decreases with plot length (Joel et al., 2002; Parsons et al., 2006). However, the SCS-CN model is unable to take the effect of plot length on runoff into consideration. A potential solution to this problem is to incorporate established scaleparameter relationships into the model. Moreover, agricultural fields are generally longer. The applicability of the developed SCS-CN model on relatively long fields should be tested.

According to the USLE/RUSLE scheme, soil loss per unit area should increase with plot length. However, according to the literature, an increasing relationship was often not detected. For example, field observations in the Negev Highlands showed that frequency and magnitude of the specific runoff yield decreased with increasing area as a result of flow discontinuity and deposition processes along the hill- slope (Yair and Raz-Yassif, 2004). Moreno-de las Heras et al. (2010) observed that unit area sediment yield declined with increasing plot length for the undisturbed and moderately disturbed sites, but it actually increased for the highly disturbed sites, which was especially clear under highintensity rainfall conditions in a Mediterranean dry environment. Therefore, the plot-scale effects of runoff and erosion were dependent on the extent of degradation. Liu et al. (2012) found that soil loss rates decreased with the plot area in Group 2 and Group 3 plots with longer restoration time, but they increased over an area threshold in Group 1 plot located at the early stage of revegetation, which was not totally consistent with the USLE/RUSLE model. One of the main reasons for the complex plot-scale effects of soil loss is the connectivity and distribution of runoff and sediment source and sink areas on hillslope (Yair and Raz-Yassif, 2004; Parsons et al., 2006; Moreno-de las Heras et al., 2010). Therefore, not only plot length, but the other factors such as rainfall regime, soil property, and vegetation cover contribute to scale variations of runoff and soil loss. As indicated by Kinnell (2008), considering the runoff coefficient as a factor in the RUSLE model can capture the plot-scale effects of soil loss to some extent, which is also proved by the simulation results of modified RUSLE model with the measured runoff ratio in this study. However, as a conceptual model, the physical base and model structure make the modified RUSLE model difficult to fully incorporate the scale variations of sediment yield, and further studies are needed to test its applicability on long plots.

Besides the two major limitations of the developed models mentioned above, there still are several issues that need further investigation. Firstly, rainfall intensity and rainfall duration have great impact on the quantity of runoff, but they were not considered in the modified SCS-CN model. More efforts are needed to account for the temporal variation of rainfall, such as done in Mishra et al. (2008) and Suresh Babu and Mishra (2012). Secondly, it is difficult to independently determine the introduced empirical coefficients in the modified RUSLE model. Systematic field experiments should be conducted to establish quantitative relationships between the empirical coefficients and known variables such as soil texture, land cover, plot length and slope. Thirdly, sediment deposition due to changes in slope gradient was ignored in the modified RUSLE model. More attention should be paid to couple the modified RUSLE model with an appropriate sediment transport model, as done in RUSLE2. Finally, further studies are needed to extend the modified SCS-CN and RUSLE models to catchment or watershed scale for longterm continuous and spatial distributed hydrologic simulation. It is very useful to evaluate the impacts of land use and climate change on hydrological cycles. 


\section{Conclusions}

In this study, the modified SCS-CN and RUSLE models were coupled to predict event runoff and soil loss from restoring vegetation plots in the Loess Plateau of China. The effects of antecedent moisture condition on runoff production (Eq. 6) and initial abstraction (Eq. 11) were explicitly accounted for in the modified SCS-CN model. Antecedent moisture condition, slope gradient and initial abstraction ratio were incorporated to determine the curve number, and two initial abstraction coefficient values $(\lambda=0.05,0.2)$ were used in the SCS-CN model. In the modified RUSLE model, direct effect of runoff on event soil loss was considered by adopting a rainfall-runoff erosivity index $\left(Q_{\mathrm{R}} \mathrm{EI}_{30}\right)$ to replace the traditional rainfall erosivity factor $\left(\mathrm{EI}_{30}\right)$ (Eq. 14). By determining the runoff ratio $Q_{\mathrm{R}}$, the rainfall-runoff-erosion modeling was linked with predicted runoff of the modified SCS-CN model.

The simulation results indicated that the original SCS$\mathrm{CN}$ model $(\lambda=0.05,0.2)$ and modified SCS-CN model $(\lambda=0.2)$ underestimated the event runoff, especially for the rainfall events that have large 5-day antecedent precipitation. Compared to these three models, the modified SCS$\mathrm{CN}$ model $(\lambda=0.05)$ accurately predicted event runoff with Nash-Sutcliffe model efficiency (EF) greater than 0.85 . The original RUSLE model overestimated low values of measured soil loss and underpredicted the high values, whereas the modified RUSLE model could well predict both the small and large event soil loss with EF over 0.70 .

It can be found from this study that the antecedent moisture should be directly incorporated into the SCS-CN model and $\lambda=0.05$ is suitable for the initial abstraction coefficient in the study area. Direct consideration of runoff in the event rainfall-runoff erosivity can substantially improve the capacity of the RUSLE model to predict event soil loss. Coupling the modified SCS-CN and RUSLE models has great practical importance for runoff and soil loss simulation in the Loess Plateau. The main advantages, limitations and future study scopes of the proposed models were also discussed in detail. This evaluation is useful for future model applications and additional model development.

Acknowledgements. This research was financially supported by the National Natural Science Foundation of China (Grant Nos. 41101096, 40930528 and 41171156), Open Fund from State Key Laboratory of Soil Erosion and Dryland Farming on the Loess Plateau (Grant No. 10501-280), and the CAS/SAFEA International Partnership Program for Creative Research Teams of "Ecosystem Processes and Services". We thank the editor Lixin Wang, the two anonymous reviewers and Luca Brocca for their constructive comments which improved the overall quality of the manuscript.

Edited by: L. Wang

\section{References}

Ali, G. A. and Roy, A. G.: A case study on the use of appropriate surrogates for antecedent moisture conditions (AMCs), Hydrol. Earth Syst. Sci., 14, 1843-1861, doi:10.5194/hess-14-18432010, 2010.

Bagarello, V., Di Piazza, G. V., Ferro, V., and Giordano, G.: Predicting unit plot soil loss in Sicily, south Italy, Hydrol. Process., 22, 586-595, 2008.

Bagarello, V., Ferro, V., and Giordano, G.: Testing alternative erosivity indices to predict event soil loss from bare plots in Southern Italy, Hydrol. Process., 24, 789-797, 2010.

Baltas, E. A., Dervos, N. A., and Mimikou, M. A.: Technical Note: Determination of the SCS initial abstraction ratio in an experimental watershed in Greece, Hydrol. Earth Syst. Sci., 11, 18251829, doi:10.5194/hess-11-1825-2007, 2007.

Bartley, R., Corfield, J. P., Abbott, B. N., Hawdon, A. A., Wilkinson, S. N., and Nelson, B.: Impacts of improved grazing land management on sediment yields, Part 1: hillslope processes, J. Hydrol., 389, 237-248, 2010.

Beasley, D. B., Huggins, L. F., and Monke, E. J.: ANSWERS: a model for watershed planning, Trans. ASAE, 23, 938-944, 1980.

Beck, H. E., de Jeu, R. A. M., Schellekens, J., van Dijk, A. I. J. M., and Bruijnzeel, L. A.: Improving Curve Number based storm runoff estimates using soil moisture Proxies, IEEE J. Sel. Top. Appl. Earth Observ. Remote Sens, 2, 1939-1404, 2010.

Brocca, L., Melone, F., Moramarco, T., and Morbidelli, R.: Antecedent wetness conditions based on ERS scatterometer data, J. Hydrol., 364, 73-87, 2009a.

Brocca, L., Melone, F., Moramarco, T., and Singh, V. P.: Assimilation of observed soil moisture data in storm rainfall-runoff modeling, J. Hydrol Eng. ASCE, 14, 153-165, 2009b.

Brocca, L., Melone, F., Moramarco, T., Wagner, W., Naeimi, V., Bartalis, Z., and Hasenauer, S.: Improving runoff prediction through the assimilation of the ASCAT soil moisture product, Hydrol. Earth Syst. Sci., 14, 1881-1893, doi:10.5194/hess-141881-2010, 2010.

Brocca, L., Melone, F., and Moramarco, T.: Distributed rainfallrunoff modeling for flood frequency estimation and flood forecasting, Hydrol. Process., 25, 2801-2813, 2011a.

Brocca, L., Melone, F., Moramarco, T., and Wagner, W.: What perspective in remote sensing of soil moisture for hydrological applications, Proc. SPIE 8174, 81740A, doi:10.1117/12.898034, 2011 b.

Brown, L. C. and Foster, G. R.: Storm erosivity using idealized intensity distribution, Trans. ASAE, 30, 379-386, 1987.

Cao, S. X., Chen, L., and Yu, X. X.: Impact of China's Grain for Green Project on the landscape of vulnerable arid and semi-arid agricultural regions: a case study in northern Shaanxi Province, J. Appl. Ecol., 46, 536-543, 2009.

Coustau, M., Bouvier, C., Borrell-Estupina, V., and Jourde, H.: Flood modelling with a distributed event-based parsimonious rainfall-runoff model: case of the karstic Lez river catchment, Nat. Hazards Earth Syst. Sci., 12, 1119-1133, doi:10.5194/nhess-12-1119-2012, 2012.

Descheemaeker, K., Posen, J., Borselli, L., Nyssen, J., Raes, D., Haile, M., Muys, B., and Deckers, J.: Runoff curve numbers for steep hillslopes with natural vegetation in semi-arid tropical highland, northern Ethiopia, Hydrol. Process., 22, 4097-4105, 2008. 
Feng, X. M., Sun, G., Fu, B. J., Su, C. H., Liu, Y., and Lamparski, H.: Regional effects of vegetation restoration on water yield across the Loess Plateau, China, Hydrol. Earth Syst. Sci. Discuss., 9, 4161-4191, doi:10.5194/hessd-9-4161-2012, 2012.

Fu, B. J., Zhao, W. W., Chen, L. D., Zhang, Q. J., Lü, Y. H., Gulick, H., and Poesen, J.: Assessment of soil erosion at large watershed scale using RUSLE and GIS: a case study in the Loess Plateau of China, Land Degrad. Dev., 16, 73-85, 2005.

Fu, S., Zhang, G., Wang, N., and Luo, L.: Initial abstraction ratio in the SCS-CN method in the Loess Plateau of China, Trans. ASABE, 54, 163-169, 2011.

Garcia-Estringana, P., Alonso-Blázquez, N., Marques, M. J., Bienes, R., and Alegre, J.: Direct and indirect effects of Mediterranean vegetation on runoff and soil loss, Eur. J. Soil Sci., 61, 174-185, 2010.

Hawkins, R. H., Hjelmfelt, A. T., and Zevenbergen, A. W.: Runoff probability, storm depth and curve numbers, J. Irrig. Drain. Eng. ASCE, 111, 330-340, 1985.

Hawkins, R. H., Jiang, R., Woodward, D. E., Hjelmfelt, A. T., Van Mullem, J. A., and Quan, Q. D.: Runoff curve number method: examination of the initial abstraction ratio, in: Proceedings of the Second Federal Interagency Hydrologic Modeling Conference, Las Vegas, US Geological Survey, Lakewood, Colorado, 2002.

Huang, M. B., Gallichand, J., Wang, Z. L., and Goulet, M.: A modification to the Soil Conservation Service curve number method for steep slopes in the Loess Plateau of China, Hydrol. Process., 20, 579-589, 2006.

Huang, M. B., Gallichand, J., Dong, C. Y., Wang, Z. L., and Shao, M. A.: Use of moisture data and curve number method for estimating runoff in the Loess Plateau of China, Hydrol. Process., 21, 1471-1481, 2007.

Jiang, Z. S., Wang, Z. Q., and Liu, Z.: Quantitative study on spatial variation of soil erosion in a small watershed in the loess hilly region, J. Soil Water Conserv., 2, 1-9, 1996 (in Chinese).

Joel, A., Messing, I., Seguel, O., and Casanova, M.: Measurement of surface water runoff from plots of two different sizes, Hydrol. Process., 16, 1467-1478, 2002.

Kinnell, P. I. A.: Why the universal soil loss equation and the revised version of it do not predict event erosion well, Hydrol. Process., 19, 851-854, 2005.

Kinnell, P. I. A.: Runoff dependent erosivity and slope length factors suitable for modeling annual erosion using the Universal Soil Loss Equation, Hydrol. Process., 21, 2681-2689, 2007.

Kinnell, P. I. A.: Comment on "Scale relationships in hillslope runoff and erosion" (Earth Surface Processes and Landforms 31: 1364-1383 (2006)), Earth Surf. Proc. Land., 33, 1632-1636, 2008.

Kinnell, P. I. A.: Comment on "SCS-CN based time distributed sediment yield model" by Tyagi et al. Journal of Hydrology 352 (2008) 388-403, J. Hydrol., 367, 293-294, 2009.

Kinnell, P. I. A.: Event soil loss, runoff and the Universal Soil Loss Equation family of models: A review, J. Hydrol., 385, 384-397, 2010.

Kinnell, P. I. A. and Risse, L. M.: USLE-M: Empirical modelling rainfall erosion through runoff and sediment concentration, Soil Sci. Soc. Am. J., 62, 1667-1672, 1998.

Knisel, W. G.: CREAMS: a field-scale model for chemical, runoff and erosion from agricultural management systems, Conservation Research Report, vol. 26, South East Area, US Department of Agriculture, Washington, DC, 1980.

Li, Y., Poesen, J., Yang, J. C., Fu, B., and Zhang, J. H.: Evaluating gully erosion using ${ }^{137} \mathrm{Cs}$ and ${ }^{210} \mathrm{~Pb} /{ }^{137} \mathrm{Cs}$ ratio in a reservoir catchment, Soil Till. Res., 69, 107-115, 2003.

Liu, G. S., Jiang, N. H., Zhang, L. D., and Liu, Z. L.: Soil Physical and Chemical Analysis and Description of Soil Profile, Chinese Standardization Publishing House, Beijing, 1996 (in Chinese).

Liu, Y., Fu, B. J., Lü, Y. H., Wang, Z., and Gao, G. Y.: Hydrological responses and soil erosion potential of abandoned cropland in the Loess Plateau, China, Geomorphology, 138, 404-414, 2012.

Lü, Y. H., Fu, B. J., Feng, X. M., Zeng, Y., Liu, Y., Chang, R. Y., Sun, G., and Wu, B. F.: A policy-driven large scale ecological restoration: quantifying ecosystem services changes in the Loess Plateau of China, PLoS ONE, 7, e31782, doi:10.1371/journal.pone.0031782, 2012.

Michel, C., Andréassian, V., and Perrin, C.: Soil conservation service curve number method: how to mend a wrong soil moisture accounting procedure?, Water Resour. Res., 41, W02011, doi:10.1029/2004WR003191, 2005.

Mishra, S. K. and Singh, V. P.: SCS-CN-based hydrologic simulation package, in: Mathematical Models in Small Watershed Hydrology and Applications, edited by: Singh, V. P. and Frevert, D. K., Water Resources Publications, Littleton, Colorado, 391-464, 2002.

Mishra, S. K. and Singh, V. P.: Soil Conservation Service Curve Number (SCS-CN) Methodology, Kluwer Academic Publishers, Dordrecht, The Netherlands, 2003.

Mishra, S. K., Sahu, R. K., Eldho, T. I., and Jain, M. K.: An improved Ia-S relation incorporating antecedent moisture in SCSCN methodology, Water Resour. Manag., 20, 643-660, 2006 a.

Mishra, S. K., Tyagi, J. V., Singh, V. P., and Sing, R.: SCS-CN modeling of sediment yield, J. Hydrol., 324, 301-322, 2006b.

Mishra, S. K., Pandey, R. P., Jain, M. K., and Singh, V. P.: A rain duration and modified AMC-dependent SCS-CN procedure for long duration rainfall-runoff events, Water Resour. Manag., 22, 861-876, 2008.

Moreno-de las Heras, M., Merino-Martín, L., and Nicolau, J. M.: Effect of vegetation cover on the hydrology of reclaimed mining soils under Mediterranean-Continental climate, Catena, 77, 3947, 2009.

Moreno-de las Heras, M., Nicolau, J. M., Merino-Martín, L., and Wilcox, B. P.: Plot-scale effects on runoff and erosion along a slope degradation gradient, Water Resour. Res., 46, W04503, doi:10.1029/2009WR007875, 2010.

Nearing, M. A.: A single continuous function for slope steepness influence on soil loss, Soil Sci. Soc. Am. J., 61, 917-919, 1997.

Neitsch, S. L., Arnold, J. G., Kiniry, J. R., and Williams, J. R.: Soil and water assessment tool theoretical documentation, Texas Water Resources Institute, College Station, TX, 2005.

Parsons, A. J., Brazier, R. E., Wainwright, J., and Powell, D. M.: Scale relationships in hillslope runoff and erosion, Earth Surf. Proc. Land., 31, 1384-1393, 2006.

Podwojewski, P., Janeau, J. L., Grellier, S., Valentin, C., Lorentz, S., and Chaplot, V.: Influence of grass soil cover on water runoff and soil detachment under rainfall simulation in a sub-humid South African degraded rangeland, Earth Surf. Proc. Land., 36, 911922, 2011.

Ponce, V. M. and Hawkins, R. H.: Runoff curve number: has it reached maturity?, J. Hydrol Eng. ASCE, 1, 11-18, 1996. 
Rendard, K. G., Foster, G. R., Weesies, G. A., McCool, D. K., and Yoder, D. C.: Predicting Soil Erosion by Water: A Guide to Conservation Planning with the Revised Universal Soil Loss Equation (RUSLE), Agricultural Handbook, No. 703, US Department of Agriculture, Washington, DC, 1997.

Risse, L. M., Nearing, M. A., Nicks, A. D., and Laflen, J. M.: Error assessment in the Universal Soil Loss Equation, Soil Sci. Soc. Am. J., 57, 825-833, 1993.

Sahu, R .K., Mishra, S. K., and Eldho, T. I.: An improved AMCcoupled runoff curve number model, Hydrol. Process., 24, 2834 2839, 2010.

Sharpley, N. and Williams, J. R. (Eds.): EPIC-Erosion Productivity Impact Calculator: 1. Model Documentation, USDA Tech. Bull. No. $1768,1990$.

Shen, Y. F., Qin, Q. J., and Wu, Y. H.: Researches of the effects of vegetation types on soil erosion on Loess Plateau, Acta Agriculturae Boreali-occidentails Sinica, 12, 5-8, 2003 (in Chinese).

Shi, Z. H., Chen, L. D., Fang, N. F., Qin, D. F., and Cai, C. F.: Research on the SCS-CN initial abstraction ratio using rainfallrunoff event analysis in the Three Gorges Area, China, Catena, 77, 1-7, 2009.

Suresh Babu, P. and Mishra, S. K.: An improved SCS-CNinspired model, J. Hydrol. Eng., doi:10.1061/(ASCE)HE.19435584.0000435, in press, 2012.

Tiwari, A. K., Rosse, L. M., and Nearing, M. A.: Evaluation of WEPP and its comparison with USLE and RUSLE, Trans. ASAE, 43, 1129-1135, 2000.

Tramblay, Y., Bouvier, C., Martin, C., Didon-Lescot, J.-F., Todorovik, D., and Domergue, J.-M.: Assessment of initial soil moisture conditions for event-based rainfall-runoff modeling, J. Hydrol., 387, 176-187, 2010.

Tramblay, Y., Bouvier, C., Ayral, P.-A., and Marchandise, A.: Impact of rainfall spatial distribution on rainfall-runoff modelling efficiency and initial soil moisture conditions estimation, Nat. Hazards Earth Syst. Sci., 11, 157-170, doi:10.5194/nhess-11157-2011, 2011.

USDA-NRCS: National Engineering Handbook, Part 630 Hydrology, Chapter 9, Hydrological Soil-Cover Complexes, US Government Printing Office, Washington, DC, 2004.
Wang, L., D’Odorico, P., Evans, J. P., Eldridge, D., McCabe, M. F., Caylor, K. K., and King, E. G.: Dryland ecohydrology and climate change: critical issues and technical advances, Hydrol. Earth Syst. Sci. Discuss., 9, 4777-4825, doi:10.5194/hessd-94777-2012, 2012.

Wang, Y. F., Fu, B. J., Chen, L. D., Lü, Y. H., and Luo, C. Y.: Effects of land use change on soil erosion intensity in small watershed of Loess Hilly Region: A quantitative evaluation with 137-Cesium tracer, Chinese Journal of Applied Ecology, 20, 1571-1576, 2009 (in Chinese).

Wei, W., Chen, L. D., and Fu, B. J.: Responses of water erosion to rainfall extremes and vegetation types in a loess semiarid hilly area, NW China, Hydrol. Process., 23, 1780-1791, 2009a.

Wei, W., Chen, L. D., and Fu, B. J.: Effects of rainfall change on water erosion processes in terrestrial ecosystems: a review, Prog. Phys. Geogr., 33, 307-318, 2009 b.

Wischmeier, W. H. and Smith, D. D.: Predicting Rainfall Erosion Losses: A Guide to Conservation Planning, Agricultural Handbook, No. 537, US Department of Agriculture, Washington, DC, 1978.

Xiao, B., Wang, Q. H., Fan, J., Han, F. P., and Dai, Q. H.: Application of the SCS-CN model to runoff estimation in a small watershed with high spatial heterogeneity, Pedosphere, 21, 738-749, 2011.

Yair, A. and Raz-Yassif, N.: Hydrological processes in a small arid catchment: scale effects of rainfall and slope length, Geomorphology, 61, 155-169, 2004.

Young, R. A., Onstad, C. A., Bosch, D. D., and Anderson, W. P.: AGNPS: a nonpoint-source pollution model for evaluating agricultural watersheds, J. Soil Water Conserv., 44, 168-173, 1989.

Zhang, X. C. and Liu, W. Z.: Simulating potential response of hydrology, soil erosion, and crop productivity to climate change in Changwu tableland region on the Loess Plateau of China, Agr. Forest Meteorol., 131, 127-142, 2005.

Zhang, Y., Liu, B. Y., Zhang, Q. C., and Xie, Y.: Effect of different vegetation types on soil erosion by water, Acta Botanica Sinica, 45, 1204-1209, 2003. 